\title{
REVIEW
}

\section{Evidence of intra- and inter-oceanic regional differences in the early life history of reef- associated fishes*}

\author{
R. E. Thresher ${ }^{1}$, E. B. Brothers ${ }^{2}$ \\ ${ }^{1}$ CSIRO Marine Laboratories, GPO Box 1538, Hobart, Tasmania 7001, Australia \\ ${ }^{2}$ EFS Consultants, 3 Sunset West, Ithaca, New York 14850, USA
}

\begin{abstract}
Data on a variety of early life history features among coral reef-associated fishes are reviewed and assessed for evidence of consistent regional intra-oceanic and inter-oceanic variation. The data currently available focus on interspecific, rather than intraspecific variation, and on demersal, rather than pelagic spawning families of fishes. Although data for comparisons are still sparse, the information available suggests that sizes of eggs produced, sizes of newly hatched larvae, durations of the planktonic larval stages and rates of larval growth, at least, can vary on spatial scales that range from across reefs to among oceans. Egg size, size of newly hatched larvae and planktonic duration appear to co-vary within families, which suggests they are not evolutionarily independent. No single factor is likely to underlie the range of regional variations apparent. We speculate on the causes of, in particular, inter-oceanic differences in life history features, review evidence for and against these hypotheses, and suggest means whereby they can be tested.
\end{abstract}

\section{INTRODUCTION}

Research on coral-reef fishes centers on 2 areas: the tropical western Atlantic and the tropical western and central Pacific. The results of studies in one area are frequently compared directly with those in the other (e.g. Bohnsack \& Talbot 1980, Gladfelter et al. 1980, Talbot \& Gilbert 1981), and integrated to generate a broader understanding of the factors that determine the structure and diversity of reef fish communities (e.g. Ehrlich 1975, Smith 1978, Sale 1980). An assumption implicit in the integration of such studies, or indeed of studies from different regions within the same ocean, is that the biology of confamilial fishes in different areas is fundamentally the same. This assumption seems reasonable, given the broad taxonomic overlap of the reef-associated fish fauna around the world. Few families are restricted to only one region, and in most cases overlap is extensive at the

\footnotetext{
- This review originates from a UNESCO/COMAR workshop held in Fiji comparing Atlantic and Pacific tropical coastal ecosystems
}

generic level (Ekman 1953, Briggs 1974). Moreover, confamilial fishes in different areas are not only morphologically alike (e.g. Burgess 1978), but are also alike behaviorally (e.g. Thresher 1976 vs Low 1971; see also Robertson \& Hoffman 1977, Moyer et al. 1983, Thresher 1984) and appear to interact with the reef in much the same way, e.g. algal 'farming' by pomacentrids in the western Atlantic, Eastern Pacific and Indo-west Pacific (Brawley \& Adey 1977, Montgomery 1980, Lassuy 1980, respectively).

However, few direct, quantitative comparisons have been made of the behavior, ecology or physiology of related fishes inhabiting coral reefs in different parts of the world (see reviews in Sale 1980, Parrish 1989, Thresher in press). Even less work has focussed on the possibility of regional differences in life histories. Several studies have suggested that spawning periodicity varies between sites in a number of families (see Johannes 1978). Randall (1961) reported that the size at settlement for acronurus Acanthurus triostegus varies between sites within the tropical Pacific, apparently as a function of water temperature (higher temperatures = smaller fish at settlement). Victor (1986) noted that the duration of the planktonic larval stages of Hawaiian 
endemic labrids appeared to be longer than those of related species at Guam. Subsequently, Thresher et al. (1989) reported that planktonic durations of pomacentrids found on the Pacific Plate (including Hawaii) averaged longer than those of western Pacific species not found on the Plate. Preliminary comparisons also suggested that geographic variation in planktonic duration tended to be slight within pomacentrid species.

The first inter-oceanic comparison of life history features for reef-associated fishes was by Thresher (1982), who examined sizes of eggs produced by confamilial fishes from the western Atlantic and western and central Pacific. Data for the comparison were sparse, but indicated that for at least some demersal spawning families (i.e. those in which eggs are adhesive, heavier than seawater, and usually tended by one or both parents), mean egg sizes of western and central Pacific species averaged up to an order of magnitude larger than those of their western Atlantic confamilials. In contrast, eggs produced by pelagic spawning families (i.e those in which the buoyant, usually spherical eggs are shed directly into the water column) appeared to be similar in size in the 2 regions. As egg size correlates with a number of other reproductive parameters in fishes (e.g. Blaxter 1969, Wooton 1979 , Bagarinao \& Thia-Eng 1986) and in other marine taxa (Vance 1973, Strathmann 1977), these parameters are also likely differ between the Caribbean and the western and central Pacific for some demersal spawning families. Thresher (1985) surveyed data available at the time and found some support for this hypothesis: preliminary data suggested that egg size, size of newly hatched larvae, and planktonic duration differ between related fishes on the Australian Great Barrier Reef and the tropical western Atlantic, whereas rates of larval growth and size at settlement appeared to be much the same in the 2 areas. Since then, Victor (1986) and Grimes (1987) have tested for inter-oceanic differences in, respectively, labrids and lutjanids. Victor found that the distribution of counts of pre-transition increments in labrid otoliths (an index of planktonic larval duration) did not differ significantly between species from the tropical western Atlantic and central Pacific, but tended to be higher for eastern Pacific species. Finally, Grimes (1987) found that the proportion of its maximum adult size at which a reef-associated lutjanid reached sexual maturity varies between oceans, between continental and insular habitats, and with depth.

The primary objective of the current paper is to compare quantitatively a range of early life history features for confamilial fishes from the tropical western Atlantic and western and central Pacific Oceans, incorporating into this comparison data not available for previous studies. Because family level comparisons are coarse-grained, wherever possible we extend these comparisons at the lowest taxonomic level permitted by the data. We focus specifically on the hypothesis raised by Thresher (1982), that interoceanic differences in egg sizes, but not size at settlement, imply that larvae in some families either spend more time in the plankton and/or grow faster in the tropical western Atlantic than in comparable parts of the western and central Pacific. We preface this analysis by reviewing currently available data on regional variations in early life history features for fishes within the Indo-West Pacific. Finally, we speculate on the factors that may underlie apparent intra- and interoceanic differences in the early life histories of some, but not all reef fish families.

\section{METHODS}

Some information on regional variations of early life history features could be obtained from published literature, cited in the relevant sections below. Much of the data involved in the following analyses, however, are the result of personal communications of unpublished work from a number of reef fish biologists and from our own studies, some of which have been previously published (e.g. Brothers et al. 1983, Brothers \& Thresher 1985, Thresher \& Brothers 1985, Thresher et al. 1989).

Data on egg sizes were assembled from a scattered literature (e.g. Albrecht 1969, Moe 1976, Hussein \& Higuchi 1980, see review by Thresher 1984), from personal communications, and from personal observations. In most cases, measurements were made of newly spawned, fertilized eggs using a binocular microscope and reticule. Calculations of egg volumes were based on the approximate shape of the eggs - cylindrical, spherical or hemi-spherical - and the lengths of the major and minor axes. If more than one value was available for a species, the arithmetic mean volume was used for inter-oceanic comparisons.

Information on size of larvae at hatching was obtained from published reports (reviewed by Thresher 1984) and from measurements of larvae hatched from eggs collected on the Great Barrier Reef, in the Marshall Islands, in Papua New Guinea and, in the western Atlantic, Panama. The majority of the data are based on our personal observations and reported lengths are the means of measurements of 4 to 6 larvae from a single brood. A binocular microscope and reticule were used to measure the freshly killed larvae. Information on size of newly settled fishes was obtained primarily from the literature, as was information on adult size.

Duration of the pelagic larval stage was estimated by analysis of otolith microstructure, based, in part, on specimens obtained from collections made at St. Croix 
(US Virgin Islands) and Belize in the western Atlantic, and at several sites in the western and central Pacific (Enewetok Atoll, Philippine Islands, Papua New Guinea, Japan, Hawaii, Guam, Fiji, and One Tree Island, Lizard Island and Dampier, Australia). Comparative material from the eastern Pacific was collected by $T$. Present from the Sea of Cortez. Analysis was also based, in part, on specimens obtained from the aquarium trade. As the genera examined have not yet been reared commercially in captivity, all specimens were wild-caught, and the early life history information extracted from their otoliths reflects conditions in the field. It is unlikely that conditions in captivity affect increments that have already been deposited.

Procedures for analyzing otolith microstructure were similar to those used by other workers and are detailed in Brothers \& McFarland (1981) and Brothers (1984). In all families but the labrids, lapilli were ground and polished for examination. The sagitta was used in the labrids, because of the unusually clear transition point in these otoliths; counts obtained from the lapillus did not differ from those obtained from the sagitta. Otoliths were examined at 1500 or $2800 \times$, using a transmitted light microscope, polarized light and a contrastenhancing video system. Otolith microstructure is discussed in detail by Brothers et al. (1976), Panella (1980), Brothers \& McFarland (1981), Brothers (1984) and Radtke (1984), among others. In general, the otolith develops around a primordium, which forms during embryonic development (Brothers et al. 1976, Radtke \& Dean 1982, Thresher et al. 1989), and which is set off from the remainder of the otolith by an area of nonincremental growth, the 'core'. Duration of the pelagic stage can be accurately determined by counting the number of growth increments between the core and the first major transition point (referred to as the 'settlement mark'). This transition point is typically characterized by an abrupt change in the optical density of the otolith and the width of the growth increments.

The validity of basing estimates of larval duration on otolith microstructure rests on 2 points: that growth increments form daily and that the settlement mark indicates the end of the larval stage (see Brothers et al. 1983, Thresher 1988b). Regarding the former, we have tested the hypothesis of daily formation of growth increments for the 2 major families examined, the Pomacentridae and Pomacanthidae, by examination of otoliths from laboratory-reared larvae of known age (Thresher et al. 1989 and Thresher \& Brothers 1985, Brothers pers. obs., respectively). The validity of using the settlement mark as an indicator of the end of the pelagic larval stage has been confirmed for 2 families of interest by detailed study of otoliths of newly recruiting reef fishes immediately before and after they settle to the substratum (for pomacentrids: Thresher et al. 1989; for labrids: Victor 1983) and for a third by comparing the number of increments in specimens that have just settled to the reef with the number of pre-transition increments in juvenile and adult specimens (for pomacanthids: Thresher \& Brothers 1985, also for pomacentrids: Thresher et al. 1989).

\section{RESULTS}

\section{Intra-oceanic regional variation in early life history parameters}

\section{Latitudinal variation}

Latitude correlates with intra- and interspecific variation in a range of reproductive features in fishes, including egg size, adult size, size and age of sexual maturation and frequency of spawning (e.g. Rass 1941, Marshall 1953, Barlow 1961, Edwards 1984, Thresher 1988a). Among reef-associated families, latitude-correlated variation in egg size has been documented only for those that produce demersal eggs. For such families, at least some other reproductive parameters also vary with latitude (e.g. Fig. 1). As is the case for marine invertebrates (Jablonski \& Lutz 1983), the slope of the 'latitudinal effect' increases towards the poles. Hence, latitudinal variation within the tropics may often be slight and ambiguous. Even so, in many families higher latitude species have eggs that are large relative to those of their more tropical relatives. Egg volume in the western Atlantic gobiid sub-genus Elacatinus increases $178 \%$ (largest divided by smallest) between $16^{\circ}$ and $25^{\circ} \mathrm{N}$ latitude (correlation between latitude and egg volume $r_{s}=0.95, p<0.01$ ), based on data in Colin (1975). In the Pacific, extremely large eggs characterize sub-tropical and temperate species in the chromin damselfishes (Turner \& Ebert 1962, Russell 1971), pomacentrin damselfishes (Limbaugh 1964, Honda \& Imai 1973), apogonids (Hale 1947, B. Bruce pers. comm.) and syngnathids (Kuiter 1988). Trends among pelagic spawning fishes superficially appear inconsistent. Egg size correlates with latitude in western Pacific labrids, carangids and mugiloids, for example, but not in the callionymids and serranids. Among these families, however, egg size correlates highly with adult size, and the presence or absence of a latitudinal cline in egg sizes depends primarily, if not entirely, on the extent to which adult size varies with Iatitude. Hence, the largest labrids, carangids and mugiloids for which we have data on egg sizes are temperate species, whereas the largest callionymids and serranids are tropical. An association between egg size and adult size in pelagic spawning fishes, but not those that produce demersal eggs, is 

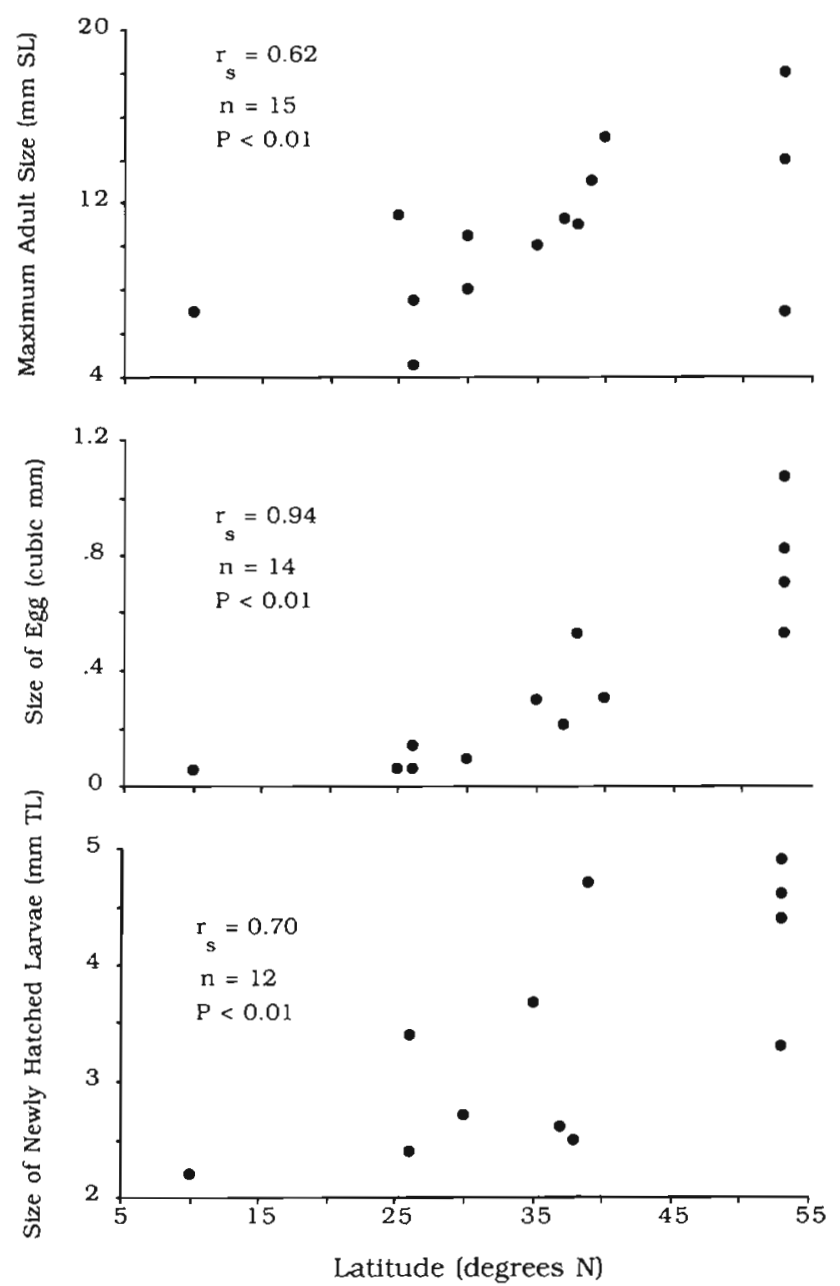

Fig. 1. Latitudinal variation in maximum adult size, egg size and sizes of newly hatched larvae among North Atlantic Blenniidae

consistent with observations by Thresher (1988a) for North Atlantic shore fish families.

We have few data as yet for analysis of intraspecific latitudinal variation in egg sizes; those we have are not compelling. Of 5 species of damselfishes sampled at 2 sites on the Australian Great Barrier Reef (Lizzard Island, at $14^{\circ} \mathrm{S}$ and One Tree Island, at $\left.23^{\circ} \mathrm{S}\right)$, the eggs of two (Pomacentrus rhodonotus and Dischistodus melanotus) were virtually identical in size at the 2 sites; one (Dischistodus pseudochrysopoecilus) had larger eggs at One Tree Island; and two (Chrysiptera biocellata and C. cyanea) had larger eggs at Lizard Island.

\section{Non-latitude-correlated variation within the Indo-Pacific}

Data for most families are still sparse; those for pelagic spawning families are rare. Hence, comments about non-latitudinal variation of early life history features within oceans must remain suggestive, at best. Nonetheless, there are indications of consistent regional variation within the Pacific for some families. In the Apogonidae, eggs produced by species endemic to Hawaii are significantly smaller than those produced by confamilials in either southern Japan or on the Australian Great Barrier Reef (Mann-Whitney U-test, $\mathrm{p}<0.01$ ) (Fig. 2). Similarly, the eggs produced by blenniids collected off the continental margins of the Indian Ocean are smaller than those reported for species sampled off tropical Australia or in Oceania. Duration of the larval stages of pomacentrids endemic to the Pacific Plate (see Springer 1982) averages longer than those found only in the western Pacific (Thresher et al. 1989). Among damselfishes, planktonic durations also vary along an inshore-offshore axis. On the central Great Barrier Reef, species found predominantly on inshore

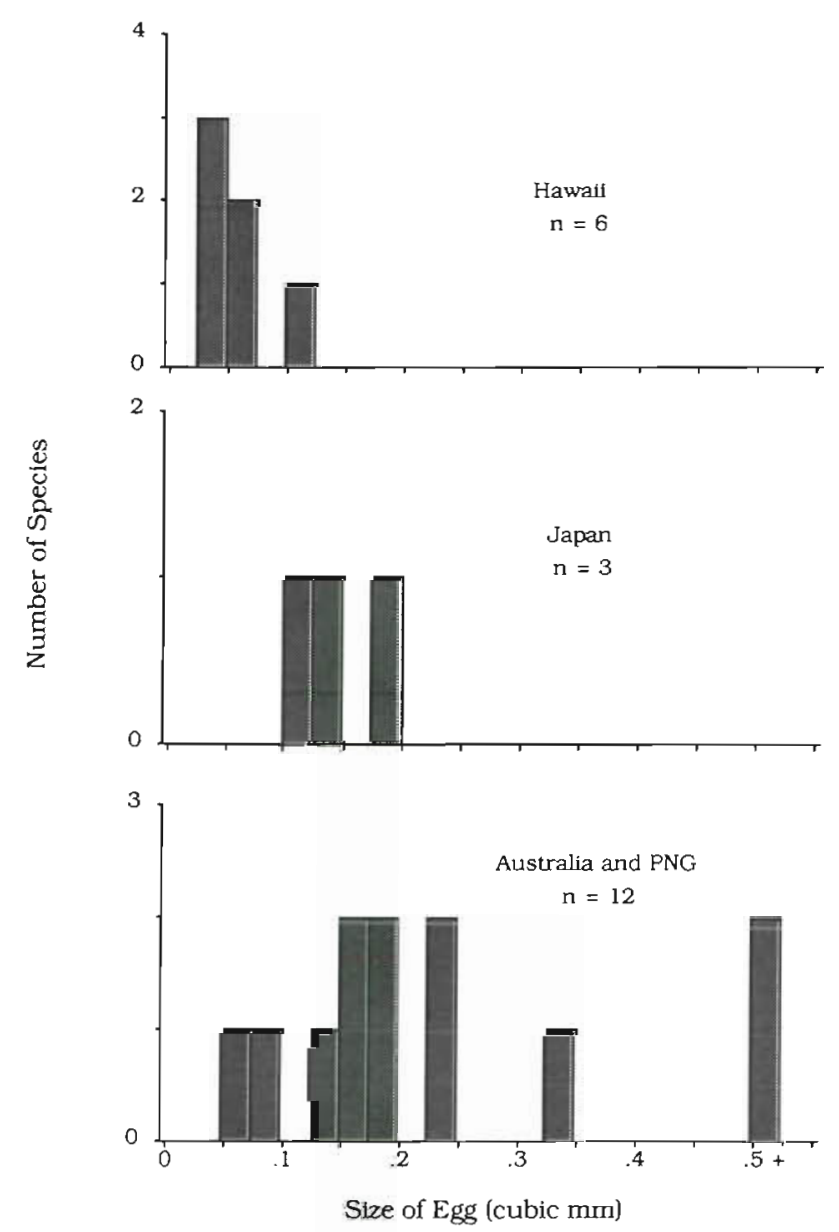

Fig. 2. Distribution of species mean values of egg sizes among apogonid species from the Hawaiian Islands, Japan, and Australia and Papua New Guinea. n: Number of species sampled in each area. Differences between distributions are significant at $p<0.01$ 
and mid-shelf reefs have relatively short planktonic durations whereas those inhabiting outer shelf and offshore reefs have consistently long planktonic durations (Fig. 3). As yet, there are not enough data to test for similar cross-shelf patterns in other families or at other sites.

Very sparse data suggest that intraspecific, regional variation in early life history features is slight in the Indo-West Pacific. As noted earlier, Randall (1961) reported regional variation in size at settlement of acronurus of Acanthurus triostegus in the Pacific; this observation has not been followed up by further study. Otherwise, the only analysis of such regional variation is that for larval duration among a few pomacentrid species by Thresher et al. (1989). Pre-transition increment counts for the anemonefish Amphiprion clarkii, for example, vary from 7 to 11 off Papua New Guinea $(\overline{\mathrm{x}}=8.9, \mathrm{n}=34)$ as compared with 7 to 10 off southern Japan ( $(\bar{x}=8.3, n=8)$. Differences between the 2 sites are not significant (Mann-Whitney U-test, $\mathrm{p}>0.1$ ). Pretransition increment counts for 7 other pomacentrid species collected at 2 or more sites also tended to overlap broadly between sites, although as in $A$. clarkii sample sizes are small and the power of statistical tests to discriminate differences is not strong. Thresher et al. (1989) did undertake a detailed regional comparison in the widely distributed species Pomacentrus coelestis, however. Specimens were obtained from 5 sites in the western and central Pacific. Pre-transition increment counts overlapped broadly among sites, but nonetheless differed significantly among them (ANOVA, $F_{4,79}$ $=4.05, \mathrm{p}<0.01)$. The lowest mean count was for specimens from Papua New Guinea $(\overline{\mathrm{x}}=18.6, \mathrm{SD}=$ 2.0, $n=19$ ) and the highest was for fishes from Lizard

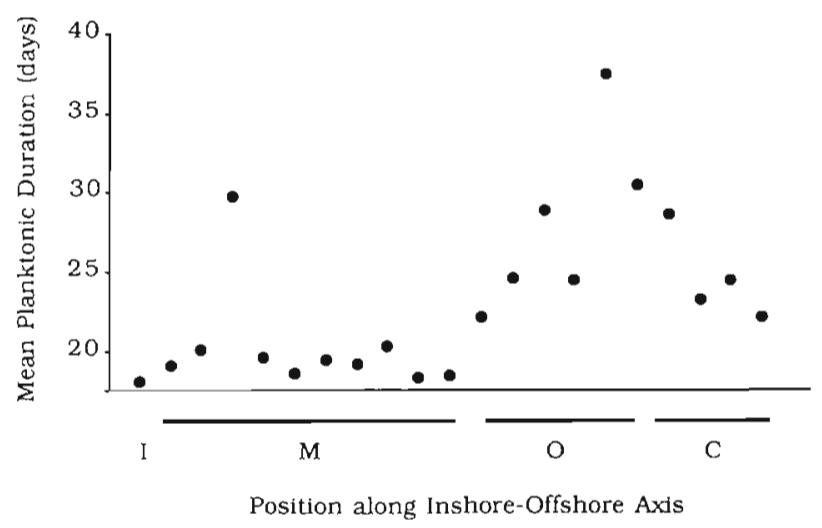

Fig. 3. Distribution of species' mean durations of the planktonic larval stage for pomacentrid species across the Great Barrier Reef (Australia). Species are arrayed along the inshore-offshore axis according to Williams (1982). Species are grouped by major habitat according to Williams as I (inshore), $M$ (Mid-shelf), O (off-shore) and C (Coral Sea)

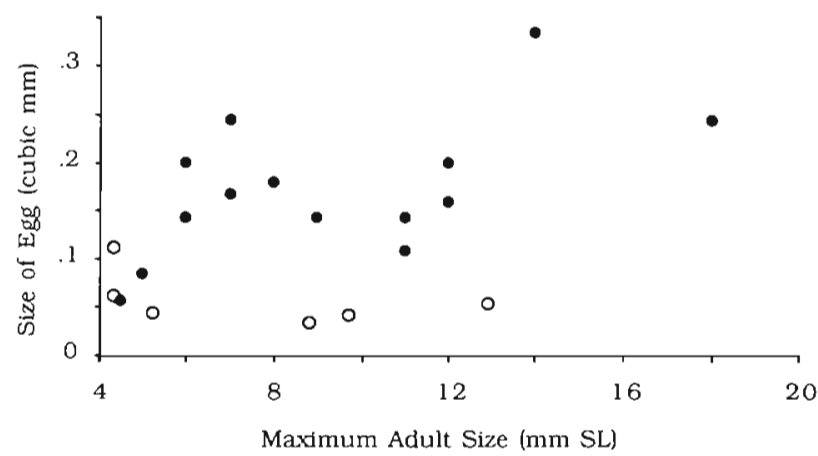

Fig. 4. Relationship between maximum adult size and egg size for apogonid species from Hawaii (o) and elsewhere in the western and central Pacific $(\bullet)$

Island, Great Barrier Reef ( $\overline{\mathrm{x}}=20.7, \mathrm{SD}=2.0, \mathrm{n}=20$ ). No comparable data sets are available for any other family of reef fishes, though the senior author is currently analyzing regional variation in reproductive parameters for several blenniid species.

In the Hawaiian Islands, as noted above, the eggs produced by endemic apogonid species are particularly small, a feature unrelated to the size of the adults (Fig. 4). Relatively small eggs also seem to characterize Hawaiian endemic blennies and, to a lesser extent, pomacentrids, though the data bases for both of these families are small. There are, as yet, insufficient data to determine if unusually small eggs (relative to adult size) characterize endemic Hawaiian species in any family of pelagic spawning fishes

Hawaiian endemic species in at least some families also appear to have planktonic larval durations that are longer than is typical for related species elsewhere in the Pacific. Such a difference, based on analysis of otolith microstructure, was first documented for angelfishes (Thresher \& Brothers 1985) (Fig. 5) and has since been described in detail for labrids by Victor (1986). Our preliminary data also suggest longer than average planktonic durations for Hawaiian endemic chaetodontids and pomacentrids. Among damselfishes, the difference appears to be slight. The Hawaiian endemic sergeant major Abudefduf abdominalis averages ca 2 pre-transition increments more than its close relative in the western Pacific, Abudefduf vaigiensis (Fig. 6); the difference between species is significant (Mann-Whitney U-test, $\mathrm{p}<0.01$ ).

\section{Inter-oceanic variation in early life history features}

\section{Egg sizes}

Data for inter-oceanic comparisons of egg sizes remain sparse for most families of reef fishes. They are 


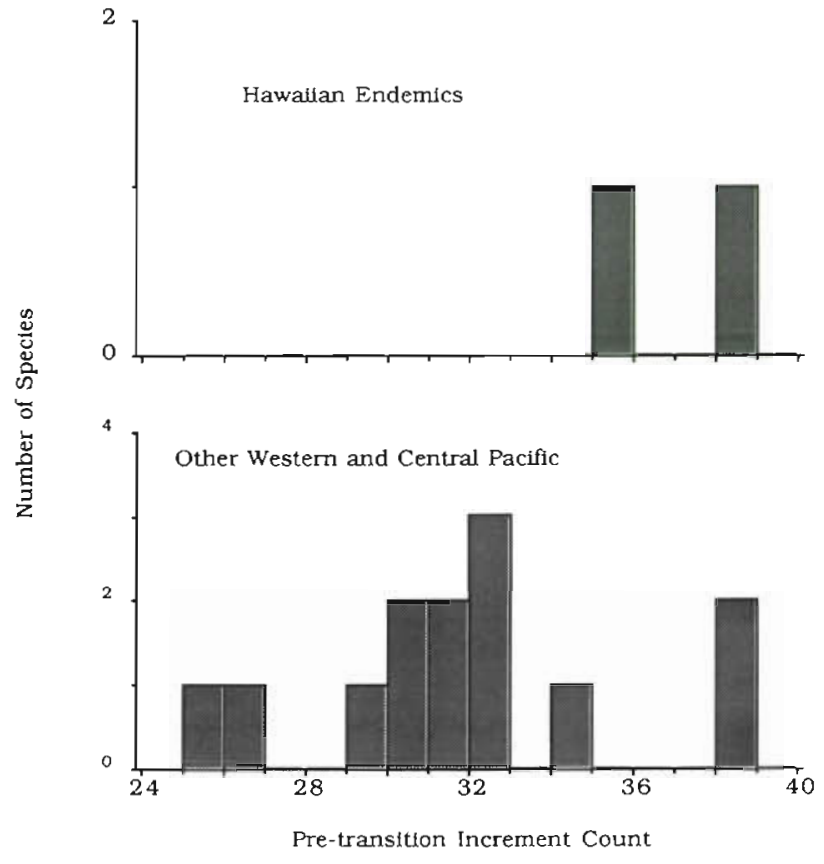

Fig. 5. Distribution of species mean planktonic durations for Hawaiian endemic and non-Hawaiian species in the pomacanthid genus Centropyge

more abundant for demersal spawning families than for those that produce planktonic eggs, due to the relative ease of collecting the eggs of the former. Our largest data sets are summarized in Table 1 . We have limited our comparisons to those families for which we have data for at least 3 species in each ocean and have minimum total sample sizes of 20 species for demersal spawners, and 10 species for pelagic spawners. These limits permit preliminary comparisons for the 4 major families of demersal spawning reef fishes, but only for 2 pelagic spawning families.

Available data continue to support the hypothesis that among most demersal spawning families average egg size are smaller for western Atlantic species than for their confamilials in the western and central Pacific. Based on species mean values, differences in egg volumes are significant for 3 of 4 demersal spawning families, the Pomacentridae (Mann-Whitney U-test, $p<0.01)$, the Apogonidae $(p<0.01)$ and the Blenniidae $(p<0.01)$. They are not significant for the demersal spawning family Gobiidae nor for the 2 pelagic spawning families examined, the Pomacanthidae and Serranidae. The Gabiidae vary more widely in egg size than any other family we have examined thus far, and no clear trends are evident in the data (for a comparable pattern regarding latitudinal variation; see Thresher 1988a). Sample sizes for the 2 families of pelagic spawners are still small, so statistical tests of regional variation in egg size are not strong; nonethe- less, egg volumes overlap more extensively for both than they do in any of the demersal spawning families, other than Gobiidae, and neither shows any indication of inter-oceanic differences in mean egg size comparable to those of the 3 demersal spawning families. Our sparse data for the eggs of eastern Pacific demersal

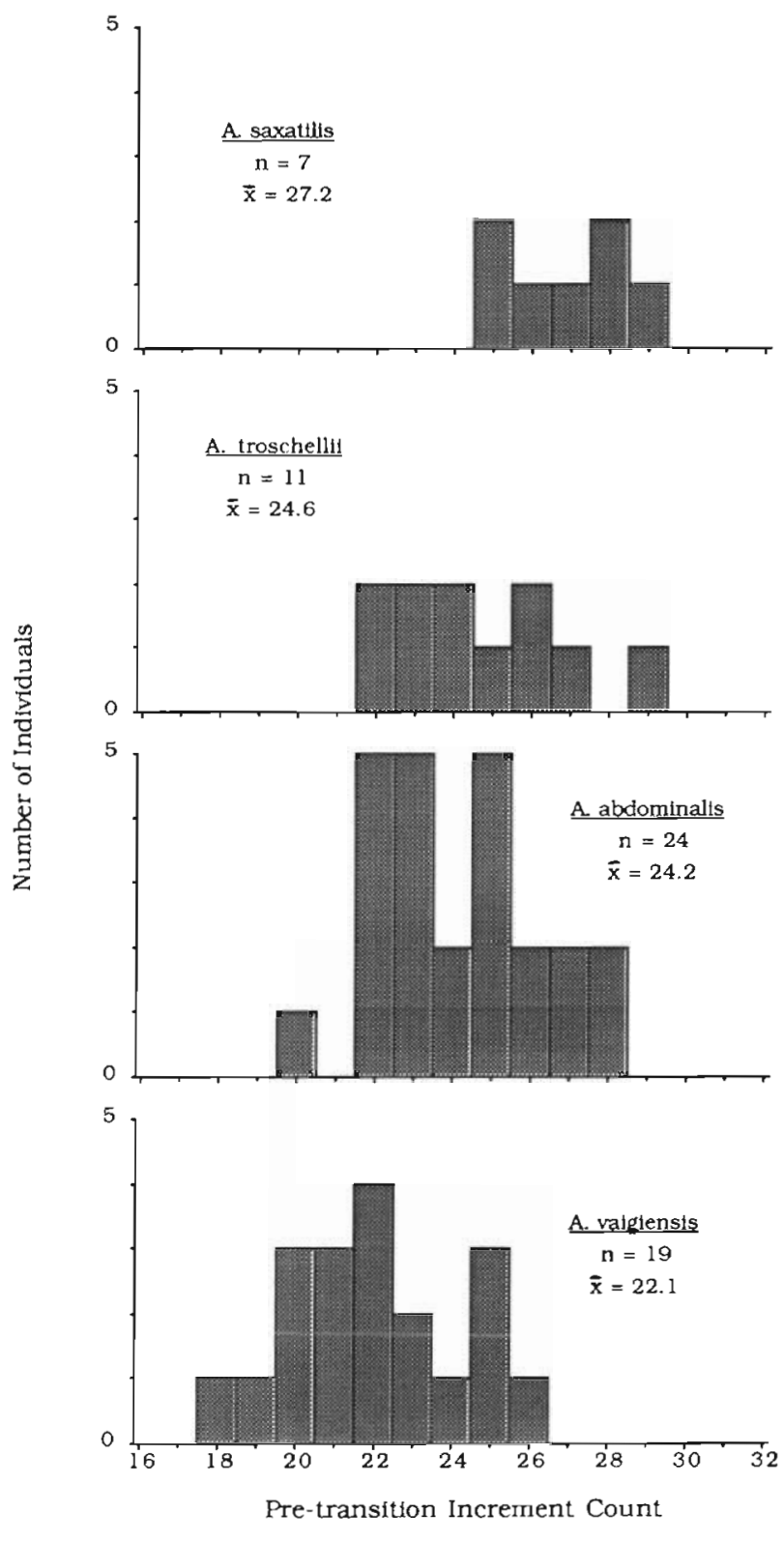

Fig. 6. Distribution of pre-transition increment counts for 4 species in the sergeant major Arten-Kreis, Abudefduf spp (Pomacentridae). A. saxatilis is found in the tropical western Atlantic; $A$. troschellii is the eastern Pacific major: $A$. abdominalis is an Hawailan endemic species; and $A$ vaigiensis occurs widely in the western and central Pacific other than Hawaii. Differences between the distributions are significant at $p<0.01$ 
Table 1. Summary of data on egg sizes (in $\mathrm{mm}^{3}$ ) for confamilial fishes from different oceanic regions. Pomacentrid data excludes Acanthochromis polyacanthus, which lacks a planktonic larval stage

\begin{tabular}{|c|c|c|c|c|c|c|}
\hline \multirow{2}{*}{ Family } & \multicolumn{2}{|l|}{ Western Atlantic } & \multicolumn{2}{|c|}{ Western \& central Pacific } & \multicolumn{2}{|l|}{ Eastern Pacific } \\
\hline & Mean (range) & $\mathrm{n}$ & Mean (range) & $\mathrm{n}$ & Mean (range) & $\mathrm{n}$ \\
\hline \multicolumn{7}{|c|}{ Demersal spawners } \\
\hline Apogonidae & $0.014(0.007-0.028)$ & 3 & $0.18 \quad(0.034-1.15)$ & 22 & & \\
\hline Blenniidae & $0.076(0.050-0.139)$ & 4 & $0.243(0.102-0.832)$ & 18 & & \\
\hline Gobiidae & $0.718(0.311-1.76)$ & 7 & $0.912(0.086-4.52)$ & 16 & $0.226(-)$ & 1 \\
\hline Pomacentridae & $0.156(0.093-0.261)$ & 8 & $0.524(0.091-1.527)$ & 37 & $0.33(0.12-0.54)$ & 2 \\
\hline Pomacentrinae & $0.185(0.104-0.261)$ & 7 & $0.429(0.112-0.898)$ & 27 & $0.33(0.12-0.54)$ & 2 \\
\hline \multicolumn{7}{|l|}{ Pelagic spawners } \\
\hline Pomacanthidae & $0.312(0.165-0.382)$ & 4 & $0.210(0.113-0.322)$ & 11 & & \\
\hline Serranidae & $0.338(0.150-0.524)$ & 7 & $0.445(0.408-0.451)$ & 3 & & \\
\hline
\end{tabular}

spawning families suggest they are generally similar in size to those in the western Atlantic (Table 1).

\section{Incubation period}

As noted above, the literature suggests that incubation period co-varies among species with egg size, and hence may exhibit comparable patterns of regional variation. Regional comparisons of incubation periods, however, are confounded by intraspecific variation due to changes in water temperature (e.g. Fricke 1974, Bell 1976), details of which are rarely available in the literature. With that limitation in mind, incubation period nonetheless correlates with egg size among pomacentrids $\left(n=16\right.$ species, $r_{5}=0.65, p<0.01$ ), based primarily on data collected by the senior author on the Great Barrier Reef and summarized in Table2. Among 'normal' species, incubation period varied from as short as $1.5 \mathrm{~d}$ for Chromis viridis to $6.5 \mathrm{~d}$ for species of Amphiprion. Although not included in the analysis, the $13 \mathrm{~d}$ incubation period of the immense egg of the demersal brooding damselfish Acanthochromis polyacanthus $\left(39.2 \mathrm{~mm}^{3}\right)$ is consistent with the hypothesis that larger eggs develop for longer periods before hatching. We have insufficient data to test for similar correlations in other families.

Despite the correlation between egg size and incubation period, the latter are not significantly shorter for Atlantic pomacentrids than they are for those in the western and central Pacific. Incubation times reported for western Atlantic species vary from 2.5 to $5.5 \mathrm{~d}(\mathrm{n}=4$ species); those for the Pacific species vary from a low of $1.5 \mathrm{~d}$ to as long as $6.5 \mathrm{~d}$ ( $\mathrm{n}=12$ species). Differences between the means are not significant for either the family as a whole or for the best represented subfamily, the Pomacentrinae (Mann-Whitney U-test, $\mathrm{p}>0.1)$.

\section{Size of newly hatched larvae}

Too few data are available for most families to test for a correlation between egg size and size of larvae at hatching. For pelagic spawning families, this analysis may be uninformative in any case, given that newly hatched pro-larvae are essentially yolk sacs with minute embryonic fishes attached to them; for such fishes, a more valuable analysis may be that between egg size and size of first-feeding larva, which is the stage at which the larvae of demersal eggs hatch. Among demersal spawning families, our only extensive data set is for the pomacentrids (Table 2), in which size of newly hatched larvae correlates highly, though apparently non-linearly, with egg size (Fig. 7). Individual variation in size at hatching has not been examined rigorously for any species, although personal observations suggest it is slight relative to interspecific differences.

A correlation between egg size and size of newly hatched larvae suggests that, in some demersal spawning families, larvae hatch at a larger average size in the

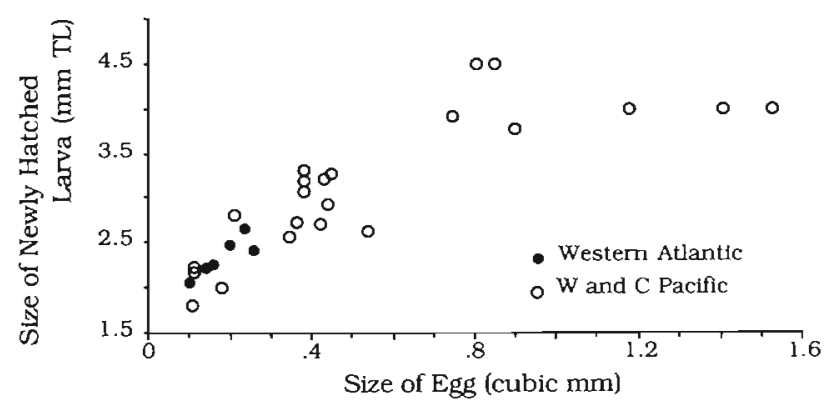

Fig. 7. Relationship between egg size and size of newly hatched larvae for western Atlantic $(\bullet)$ and western and central Pacific (o) pomacentrid species. The correlation is significant at $\mathrm{p}<0.01$ 
Table 2. Summary of early life history data for western Atlantic and western and central Pacific pomacentrids. Taxonomy follows Allen (1975). TL: Total length, SL: standard length

\begin{tabular}{|c|c|c|c|c|c|c|}
\hline Species & $\begin{array}{l}\text { Egg volume } \\
\left(\mathrm{mm}^{3}\right)\end{array}$ & $\begin{array}{c}\text { Size of newly } \\
\text { hatched larvae } \\
(\mathrm{mm} \text { TL) }\end{array}$ & $\begin{array}{l}\text { Incubation } \\
\text { period } \\
\text { (d) }\end{array}$ & $\begin{array}{l}\text { Size at } \\
\text { settlement } \\
\text { (mm SL) }\end{array}$ & $\begin{array}{l}\text { Mean duration } \\
\text { larval stage } \\
\text { (d) }\end{array}$ & $\begin{array}{l}\text { Exponential } \\
\text { growth } \\
\text { coefficient }\end{array}$ \\
\hline \multicolumn{7}{|l|}{ Western Atlantic } \\
\hline Abudefduf saxatilis & 0.261 & 2,40 & - & 10.7 & 27.2 & 0.055 \\
\hline Abudefduf taurus & 0.238 & 2.65 & 5.5 & 11.6 & 27.7 & 0.053 \\
\hline Chromis multilineatus & 0.093 & - & 2.5 & - & 33.0 & - \\
\hline Microspathodon chrysurus & 0.202 & 2.46 & 3.0 & 11.0 & 28.7 & 0.037 \\
\hline Stegastes diencaeus & 0.143 & 2.21 & - & - & 27.0 & - \\
\hline Stegastes leucostictus & 0.184 & - & - & 11.0 & 28.5 & - \\
\hline Stegastes partitus & 0.104 & 2.04 & 4.5 & 8.0 & 29.0 & 0.047 \\
\hline Stegastes planifrons & 0.163 & 2.25 & - & 8.5 & 26.8 & 0.050 \\
\hline Stegastes variabilis & - & - & - & 8.0 & 26.6 & - \\
\hline \multicolumn{7}{|l|}{ Western and central Pacific } \\
\hline Abudefduf abdominalis & 0.422 & 2.70 & 4.5 & - & 24.2 & - \\
\hline Abudefduf bengalensis & 0.450 & - & - & - & 22.8 & - \\
\hline Abudefduf coelestinus & 0.314 & -- & - & - & 21.4 & - \\
\hline Abudefduf sordidus & 0.308 & - & - & - & - & - \\
\hline Abudefduf vaigiensis & - & - & - & 10.4 & 22.1 & - \\
\hline Acanthochromis polyacanthus & 39.2 & 5.1 & 13.0 & - & 0 & - \\
\hline Amblyglyphidodon curacao & 0.745 & 3.9 & - & - & 17.3 & - \\
\hline Amblyglyphidodon leucogaster & 0.539 & - & - & - & 17.7 & - \\
\hline Amphiprion chrysopterus & 1.53 & 4.0 & 6.5 & 7.8 & - & - \\
\hline Amphiprion percula & 1.18 & 4.0 & - & 7.5 & 10.7 & 0.059 \\
\hline Amphiprion perideraion & 1.41 & 4.0 & - & 7.0 & 10.6 & 0.053 \\
\hline Amphiprion polymnus & 1.53 & - & - & 7.5 & 11.0 & - \\
\hline Amphiprion tricinctus & 1.53 & 4.0 & 6.5 & 7.8 & 10.1 & 0.066 \\
\hline Chromis atripectoralis & - & - & - & 8.9 & 20.3 & - \\
\hline Chromis ternatensis & 0.091 & - & - & - & 28.8 & - \\
\hline Chromis viridis & 0.109 & 1.8 & 1.5 & 8.2 & 24.1 & 0.063 \\
\hline Chrysiptera biocellatus & 0.441 & 2.93 & 3.5 & - & 18.6 & - \\
\hline Chrysiptera cyaneus & 0.347 & 2.56 & - & 10.0 & 17.4 & 0.078 \\
\hline Chrysiptera flavipinnis & 0.539 & 2.62 & - & - & 19.0 & - \\
\hline Chrysiptera leucopomus & 0.365 & 2.73 & - & - & 19.5 & - \\
\hline Chrysiptera rollandi & 0.383 & 3.31 & - & 10.9 & 18.5 & 0.064 \\
\hline Chrysiptera talboti & - & - & - & 9.9 & 22.0 & - \\
\hline Dascyllus albisella & 0.264 & - & - & - & 25.0 & - \\
\hline Dascyllus aruanus & - & - & - & 7.0 & 22.4 & - \\
\hline Dascyllus melanurus & 0.181 & 2.00 & 3.5 & - & 23.3 & - \\
\hline Dascyllus trimaculatus & 0.093 & - & 2.5 & - & 24.2 & - \\
\hline Dischistodus notophthalmus & 0.348 & - & 4.5 & - & 16.0 & - \\
\hline Dischistodus pseudochrysopoecilus & 0.431 & 3.20 & 3.5 & 10.0 & 15.7 & 0.073 \\
\hline Neopomacentrus azysron & - & - & - & 13.9 & 18.2 & - \\
\hline Paraglyphidodon melas & 0.898 & 3.78 & - & - & 14.8 & - \\
\hline Paraglyphidodon polyacanthus & 0.850 & 4.50 & - & - & - & - \\
\hline Plectroglyphidodon imparipinnis & 0.112 & 2.17 & - & - & - & - \\
\hline Plectroglyphidodon lacrymatus & 0.141 & - & - & - & 24.3 & - \\
\hline Plectroglyphidodon sindonis & 0.180 & - & - & - & - & - \\
\hline Pomacentrus amboinensis & 0.383 & 3.1. & - & 12.2 & 19.4 & 0.069 \\
\hline Pomacentrus arenarius & 0.451 & 3.27 & - & 1.4 .0 & 22.9 & 0.064 \\
\hline Pomacentrus australis & 0.516 & - & - & - & 25.0 & - \\
\hline Pomacentrus coelestis & 0.210 & 2.8 & 4.5 & 13.1 & 19.1 & 0.081 \\
\hline Pomacentrus moluccensis & 0.357 & - & - & - & 100 & - \\
\hline Pomacentrus pavo & - & - & - & 15.0 & 26.0 & - \\
\hline Pomacentrus rhodonotus & 0.383 & 3.06 & 3.5 & 11.9 & 19.5 & 0.070 \\
\hline Pomacentrus wardi & 0.804 & 4.50 & 4.5 & 14.3 & 20.0 & 0.058 \\
\hline Pomacentrus vaiuli & 0.550 & - & - & - & 22.5 & - \\
\hline Stegastes nigricans & 0.112 & 2.23 & - & - & 32.0 & - \\
\hline
\end{tabular}


western and central Pacific than in the western Atlantic. The strongest test we can thus far make for this hypothesis is in the Pomacentridae. Based on mean values for each species, the larvae of newly hatched pomacentrids are indeed significantly larger in the Indo-west Pacific than they are in the Atlantic (MannWhitney U-test, $p<0.05$ ) (Fig 8). This result is unaffected by restricting comparison to only the sub-family Pomacentrinae $(p<0.01)$. Inter-oceanic differences disappear once the effects of egg size are removed (ANCOVA, $p>0.1$ ).

\section{Duration of the planktonic larval stage}

The hypothesis that duration of the planktonic larval stage differs between oceans was tested by examining otolith microstructure of species of 4 families. Emphasis was placed on the Pomacentridae and Pomacanthidae, which do and do not exhibit inter-oceanic differences in egg size, respectively. Less detailed, supplemental data were collected for the demersal spawning Apogonidae and the pelagic spawning Labridae. We equate duration of the planktonic larval stage, in days, with the number of pre-transition increments in the otoliths for the Pomacentridae and with that number

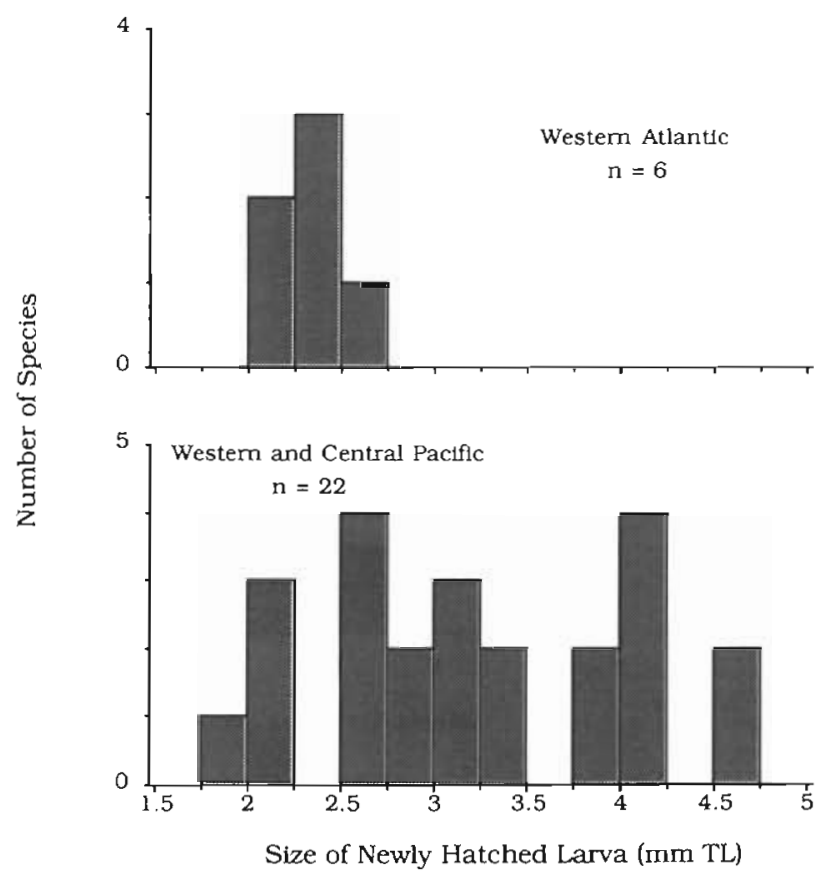

Fig. 8. Distributions of species mean sizes of newly hatched pomacentrid larvae in the tropical western Atlantic and the tropical western and central Pacific. Differences between distributions are significant at $\mathrm{p}<0.01$ plus $2 \mathrm{~d}$ for the Pomacanthidae, based on Thresher et al. (1989) and Thresher \& Brothers (1985), respectively. We assume parallel equations hold for the Apogonidae and Labridae, respectively, pending study of larval development in both families.

Pomacentridae. Mean counts of pre-transition increments varied between species from 8.4 (Premnas biaculeatus) to 37.4 (Stegastes fasciolatus). Differences between conspecifics varied across species from a low of 0 to as many as 18 increments, averaging 5.2 increments. The mean range for Pacific species, 5.2 increments (Thresher et al. 1989), did not differ significantly from that for Atlantic species, 5.1 increments (Table 3) (Mann-Whitney U-test, $p>0.1$ ). However, intraspecific variability in increment counts correlated significantly with sample size and mean duration of a species planktonic larval stage $\left(r_{\mathrm{s}}=0.52\right.$ and $\mathrm{r}_{\mathrm{s}}=0.39, \mathrm{p}<0.01$ for both). In a parametric multiple regression, sample size, mean duration and source location (Atlantic vs Pacific) are all significant predictors of intraspecific variability (for the addition of source location, $F=6.29, p<0.05$ ), with Pacific species slightly more variable intraspecifically than Atlantic ones.

Mean numbers of pre-transition increments for western and central Pacific damselfish species varied from 8.4 to $37.4(\bar{x}=20.9, n=71$ species $)$; those for western Atlantic species varied from 26.6 to 35.1 ( $\bar{x}=29.0, n=$ 11 species). The difference between grand means (the mean of species means) was highly significant (MannWhitney U-test, $p<0.001$ ). This difference is due, in part, to the presence in only the Pacific of the subfamily Amphiprioninae, which uniformly have a very short planktonic duration (Thresher et al, 1989). However, grand means also differ significantly for both pomacentrid sub-families common to the 2 regions (Fig. 9; Table 4) and for 2 of 3 common genera (Chromis and Abudefduf, the exception is Stegastes) (Table 5). The higher number of pre-transition increments suggests that western Atlantic damselfishes have a planktonic larval stage that averages about $7 \mathrm{~d}$ longer than those of related Pacific species. The range of interspecific differences is also smaller amongst Atlantic species than those from the western and central Pacific.

Pomacanthidae. Mean pre-transition counts for western and central Pacific species of angelfish varied from 17.7 to 36.8 increments ( $\bar{x}=27.0, n=38$ species) (Thresher \& Brothers 1985), as compared with 18.0 to 38.3 ( $\bar{x}=25.1, n=6$ species) (Table 3 ) for western Atlantic species (Fig. 9). Intraspecific ranges averaged 4.0 increments among Pacific species and 5.2 increments for Atlantic species, and did not differ significantly between oceans (Mann-Whitney U-test, $p>0.1$ ), irrespective of effects of sample size and mean durations (both significant correlates of intraspecific variability). Pre-transition increment counts overlap broadly 
Table 3. Number of pre-transition growth increments, sample sizes $(N)$ and sampling locations for western Atlantic species of Pomacentridae and Pomacanthidae. Site key: A, Aquarium Trade; B, Belize; C, Curaçao; V.I., US Virgin Islands

\begin{tabular}{|c|c|c|c|c|}
\hline Species & $\begin{array}{c}\text { Mean } \\
\text { pre-transition count }\end{array}$ & Range & $\mathrm{n}$ & Sampling Sites \\
\hline \multicolumn{5}{|l|}{ POMACENTRIDAE } \\
\hline Abudefduf saxatilis & 27.2 & $25-29$ & 7 & V.I. \\
\hline Abudefduf taurus & 27.7 & $27-28$ & 3 & V.I. \\
\hline Chromis cyaneus & 35.1 & $31-46$ & 24 & V.I., B, A \\
\hline Chromis insolatus & 31.7 & $29-35$ & 13 & $B$ \\
\hline Chromis multilineatus & 33.0 & - & 2 & V.I., A \\
\hline Microspathodon chrysurus & 28.7 & $27-31$ & 3 & V.I. \\
\hline Stegastes diencaeus & 27.0 & $26-28$ & 5 & V.I. \\
\hline Stegastes leucostictus & 28.5 & $27-30$ & 4 & V.I. \\
\hline Stegastes partitus & 29.0 & $28-31$ & 5 & V.I. \\
\hline Stegastes planifrons & 26.8 & $26-28$ & 5 & V.I. \\
\hline Stegastes variabilis & 26.6 & $25-30$ & 5 & V.I. \\
\hline \multicolumn{5}{|l|}{ POMACANTHIDAE } \\
\hline Centropyge argi & 36.8 & $34-40$ & 4 & $\mathrm{C}$ \\
\hline Holacanthus bermudensis & 22.7 & $22-23$ & 3 & A \\
\hline Holacanthus ciliaris & 22.4 & $20-24$ & 12 & V.I., A \\
\hline Holacanthus tricolor & 29.7 & $24-34$ & 11 & V.I., A \\
\hline Pomacanthus arcuatus & 21.3 & $20-22$ & 3 & A. \\
\hline Pomacanthus paru & 17.7 & $17-19$ & 6 & V.I., A \\
\hline
\end{tabular}

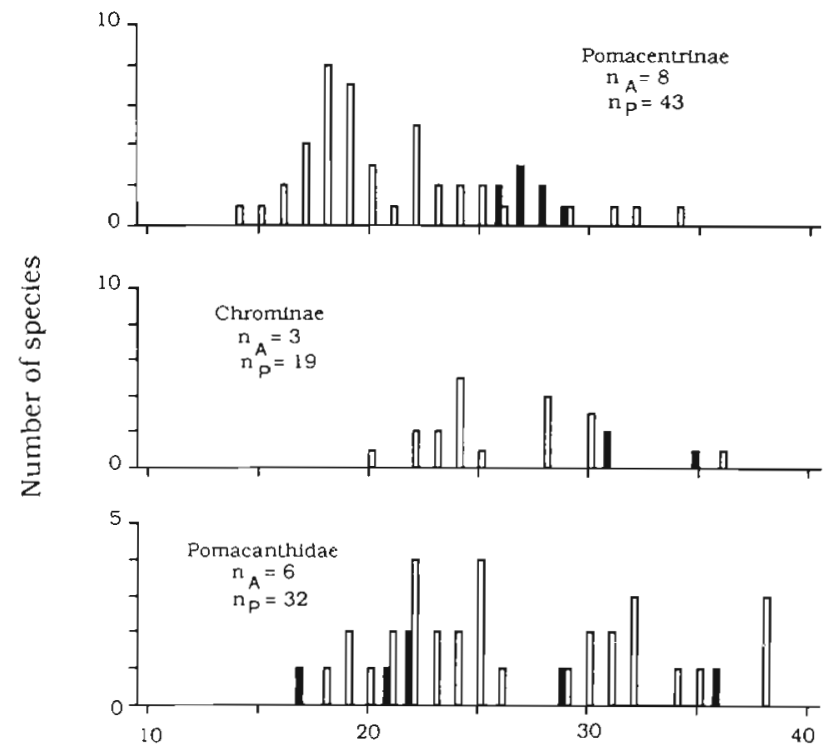

Species mean number of pre-transition increments

Fig. 9. Distributions of species mean planktonic durations for pomacentrin damselfishes, chromin damselfishes and pomacanthids in the tropical western Atlantic (solid bars) and the western and central Pacific (open bars). $\mathrm{n}_{\mathrm{A}}$ : Sample size for Atlantic species; $n_{p}$ : sample size for Pacific species. Differences between distributions in the 2 oceans are significant at $p<0.01$ for the Pomacentrinae and 0.05 for the Chrominae; differences between oceans are not significant in the Pomacanthidae between oceans and did not differ between the 2 regions for the family as a whole (Table 4 ), for either of the 2 common sub-families (Holacanthinae and Pomacanthinae), or for any of the 3 genera (Centropyge, Holacanthus and Pomacanthus) common to both regions (Table 5). Sample sizes for genera, in particular, are small, however, and the power of the test to distinguish differences is low.

Apogonidae and Labridae. We examined only a few species in the Apogonidae and Labridae. However, results of inter-oceanic comparisons are similar to those for the Pomacentridae and Pomacanthidae, respectively.

Mean pre-transition counts for 19 species of western and central Pacific apogonids, in the genera Apogon, Archamia, Siphamia, Fowleria and Cheilodipterus, varied from 16.2 to 28.4 increments. The maximum intraspecific range was 7 increments. Comparable data for 5 western Atlantic species (4 species of Apogon, and Phaeoptyx conklini) were 20.3 to 26.2 , with a maximum intraspecific range of 6 increments. Regional differences between grand means are significant at $p<0.05$ for both the family as a whole (Table 4) and for the only common genus, Apogon (Table 5). Western Atlantic species average 3.8 more pre-transition increments than Pacific species.

Our estimates of planktonic duration for 38 species of labrids ( 7 Atlantic in 4 genera, and 31 western Pacific in 12 genera) are virtually identical to those estimated for 
Table 4. Grand mean ( \pm 2 SE) of number of pre-transition growth increments of representatives of 4 families of coral-reef fishes common to the tropical western Atlantic and western and central Pacific Oceans. N: number of species in sample. Statistical significance $(p)$ determined by Mann-Whitney U-test; NS: not significant

\begin{tabular}{|lccccc|}
\hline Family & $\begin{array}{c}\text { Western Atiantic } \\
\text { No. of increments }\end{array}$ & $\mathrm{n}$ & $\begin{array}{c}\text { Western Pacific } \\
\text { No. of increments }\end{array}$ & $\mathrm{n}$ & $\mathrm{p}$ \\
\hline $\begin{array}{l}\text { Demersal spawners } \\
\text { Pomacentridae }\end{array}$ & & & & \\
$\quad$ Pomacentrinae & $29.0( \pm 1.58)$ & 11 & $20.9( \pm 1.6)$ & 71 & $<0.001$ \\
$\quad$ Chrominae & $27.7( \pm 0.66)$ & 8 & $21.0( \pm 1.38)$ & 43 & $<0.001$ \\
Apogonidae & $32.6( \pm 2.54)$ & 3 & $26.2( \pm 1.79)$ & 19 & $<0.01$ \\
Pelagic spawners & $23.0( \pm 0.87)$ & 5 & $19.2( \pm 1.87)$ & 19 & $<0.05$ \\
$\quad$ Pomacanthidae & $25.1( \pm 5.65)$ & 6 & $27.0( \pm 2.12)$ & 32 & NS \\
Labridae & $27.5( \pm 3.13)$ & 7 & $32.9( \pm 4.17)$ & 31 & NS \\
\hline
\end{tabular}

the same species by Victor (1986). Labrids are intraand interspecifically more variable than any of the other 3 families we examined. Mean pre-transition counts for the species we examined varied from 20.0 to $52.8(\overline{\mathrm{x}}=32.9)$ for Pacific species and 20.0 to $41.5(\overline{\mathrm{x}}=$ 27.5) for Atlantic species. Grand means do not differ between regions either for the family as a whole (Table 4 ) or for either of 2 genera common to samples from both areas (Table 5). Victor (1986) also did not find a significant difference between pre-transition counts for western Atlantic and central Pacific labrids.

Sergeant major 'Arten-Kreis'. Until recently, sergeant major Abudefduf saxatilis was held to be a single, circumtropically distributed species; it is now considered a complex of closely related, largely allopatric species (Allen 1976). We have data on pretransition counts for 4 species in this complex, which permit analysis of regional differences in planktonic larval durations at the lowest taxonomic level currently possible. Despite their morphological similarities and taxonomic affinities, the species differ significantly in mean larval duration (Kruskal-Wallis H-test, $\mathrm{p}<0.001$ ) (Fig. 5). Pair-wise comparisons indicate the western Atlantic species, $A$. saxatilis, has a planktonic duration significantly longer than those of the other 3 species and that of the western Pacific species, A. vaigiensis, is significantly shorter than those of any other species. The eastern Pacific species, A. troschelii, and the Hawaiian endemic species, $A$. abdominalis, do not differ significantly from one another.

A more detailed examination of the Eastern Pacific demersal spawning fishes is in preparation (Thresher \& Present unpubl.). Very preliminary results suggest that planktonic durations of eastern Pacific pomacentrids and apogonids are similar to those of their congeners in the western Atlantic, and hence are longer than those of related species in the western and central Pacific.

Table 5. Grand mean (and range) of number of pre-transition increments of representatives of 9 genera of coral-reef fishes common to western Atlantic and western and central Pacific reefs. $\mathrm{N}$ : number of species in sample. Statistical significance (p) determined by Mann-Whitney U-test; NS: not significant

\begin{tabular}{|c|c|c|c|c|c|}
\hline Species & $\begin{array}{l}\text { Western Atlantic } \\
\text { No. of increments }\end{array}$ & $\mathrm{n}$ & $\begin{array}{l}\text { Western Pacific } \\
\text { No. of increments }\end{array}$ & $\mathrm{n}$ & $\mathrm{p}$ \\
\hline \multicolumn{6}{|c|}{ Demersal spawners } \\
\hline Abudefduf & $27.4(27.1-27.7)$ & 2 & $22.0(18.3-24.2)$ & 6 & $<0.05$ \\
\hline Apogon & $23.7(20.0-26.2)$ & 4 & $21.6(13.0-28.4)$ & 11 & $<0.05$ \\
\hline Chromis & $32.6(31.0-35.1)$ & 3 & $27.1(20.3-36.1)$ & 14 & $<0.05$ \\
\hline Stegastes & $27.6(26.6-29.0)$ & 5 & $32.1(29.7-34.7)$ & 3 & $<0.05$ \\
\hline \multicolumn{6}{|l|}{ Pelagic spawners } \\
\hline Centropyge & 36.8 & 1 & $32.2(25.3-38.3)$ & 15 & NS \\
\hline Halichoeres & $21.9(20.0-24.3)$ & 4 & $28.6(21.0-37.0)$ & 4 & NS \\
\hline Holacanthus & $24.9(22.4-29.6)$ & 3 & $25.0 \quad(-)$ & 1 & NS \\
\hline Pomacanthus & $19.5(17.7-21.3)$ & 2 & $20.6(18.0-22.8)$ & 6 & NS \\
\hline Thalassoma & $39.8 \quad(-)$ & 1 & $53.1(45.2-68.5)$ & 3 & NS \\
\hline
\end{tabular}




\section{Size at settlement}

Data on sizes at settlement for Pacific species are drawn from Allen (1972), Brothers et al. (1983), Suzuki et al. (1985a) and personal observations. Few comparable data are available for Atlantic species (e.g. Potthoff et al. 1987). Hence, for purposes of a preliminary regional comparison, we assume that the minimum sizes reported for various species in detailed ecological studies conducted in the Atlantic are sizes at settlement. Such data are provided for western Atlantic damselfishes by Emery (1973), as supplemented by collections made by the junior author at St. Croix, and for western Atlantic apogonids by Dale (1978). As a result of the nature of this data set, by necessity we ignore individual variation in size at settlement.

Within the limits of the data set, differences in sizes at settlement to the substratum do not appear to differ significantly between oceans for the pomacentrids. The minimum size reported for 7 western Atlantic damselfishes averaged $9.8 \mathrm{~mm}$ SL, varying from $8.0 \mathrm{~mm}$ to $11.6 \mathrm{~mm}$. By comparison, mean size at settlement for 20 Indo-West Pacific damselfishes was $10.4 \mathrm{~mm}$, varying from 8.0 to $15.0 \mathrm{~mm}$. Size at settlement among Pacific species differs significantly among sub-families (Kruskal-Wallis H-test, $\mathrm{p}<0.01$ ) with anemonefishes settling to the substratum at a size less than that of either the Chrominae or Pomacentrinae. However, interoceanic differences in size at settlement remain insignificant even when based on only the sub-family Pomacentrinae (Mann-Whitney U-test, $p>0.1$ ). There are insufficient data to warrant inter-oceanic comparisons for the Chrominae.

Among 14 species of western Atlantic apogonids, minimum reported sizes varied from 9.7 to $22.5 \mathrm{~mm} \mathrm{SL}$, averaging $14.0 \mathrm{~mm}$; by comparison, mean size at settlement for 4 species at One Tree Island, Great Barrier Reef, varied from 8.7 to $11.9 \mathrm{~mm}$. Differences between the means are significant at $p<0.01$ (Mann-Whitney U-test), but small sample sizes and the different types of data collected in the 2 areas suggests caution in drawing conclusions.

\section{Rates of larval growth}

To test the hypothesis that rates of larval growth differ consistently between western Atlantic and western and central Pacific fishes, we calculated approximate growth rates for larvae of pomacentrids in the 2 areas, based on the difference between size at hatching and size at settlement for a given species and the mean duration of its planktonic larval stage. Individual variation in growth rates is, at this stage, unknown and is ignored for purposes of the gross scale, inter-oceanic comparison. In a previous application of this approach and in the absence of relevant data, Thresher (1985) assumed a linear growth trajectory for larval pomacentrids. However, recently available data on length-atage for laboratory-reared larvae (Suzuki et al. 1985a, b, Potthoff et al. 1987) indicate exponential growth (Fig. 10A). Consequently, for each species for which the data were available, we have calculated a mean growth coefficient based on the formula

$$
\mathrm{SL}_{\mathrm{t}}=\mathrm{L}_{\mathrm{o}} \mathrm{e}^{\mathrm{kt}}
$$

where $\mathrm{SL}_{\mathrm{t}}=$ standard length at settlement; $\mathrm{L}_{0}=$ length at hatching (usually total length; the difference between total length and notochord length would be

A
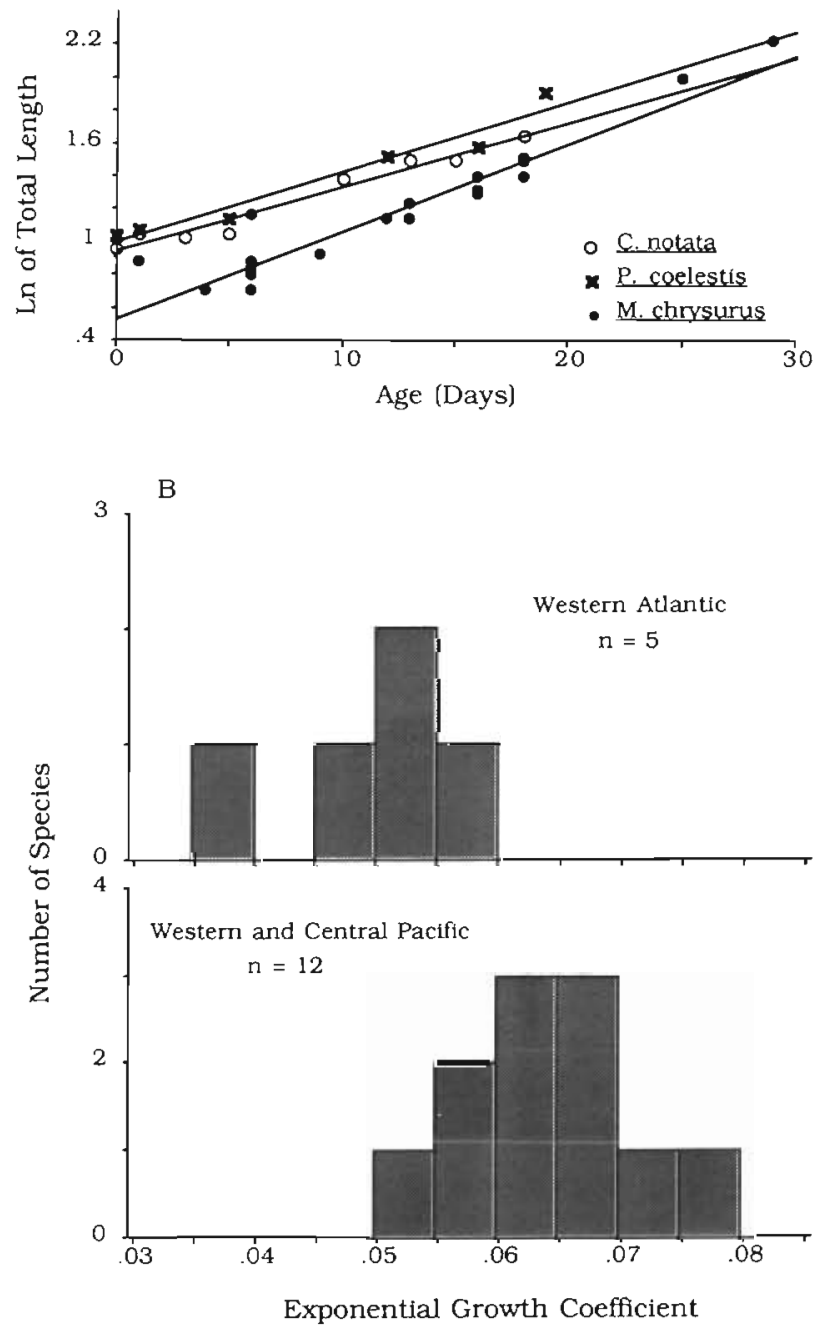

Fig. 10. (A) Regressions of In total length (in $\mathrm{mm}$ ) against age for 3 species of damselfishes reared in captivity, Chromis notata, Pomacentrus coelestis and Microspathodon chrysurus. $R^{2}$ varies between species from 0.91 to 0.96 . (B) Distribution of exponential growth coefficients estimated for tropical western Atlantic and western and central Pacific damselfishes. n: Sample sizes for each area. Differences between the distributions are significant at $p<0.05$ 
slight $) ; t=$ duration of the planktonic larval stage in days; and $\mathrm{k}=$ the growth coefficient.

Adequate data to calculate these growth coefficients are available for 5 western Atlantic and 12 Indo-West Pacific pomacentrids (Table 2).

Growth coefficients for western Atlantic species vary from a low of 0.037 to a high of 0.055 , averaging 0.048 ; those for Indo-West Pacific species vary from 0.053 to 0.081 , and average 0.066 (Fig. 10B). The means correspond to an average increase in length of 4.9 and $6.8 \%$ daily for larvae in the western Atlantic and Indo-West Pacific, respectively. Differences between the means are significant at $p<0.01$ (Mann-Whitney U-test), indicating that the larvae of western Atlantic damselfishes, on average, grow more slowly than those in the IndoWest Pacific. Restricting the comparison to only the sub-family Pomacentrinae does not alter this conclusion (Mann-Whitney U-test, $\mathrm{p}<0.01$ ).

\section{DISCUSSION}

Because of small sample sizes and incomplete geographic and systematic coverage, the power of our tests to assess regional variation is often low. At this stage, the only signals likely to be detected are those reflecting major regional differences. Even these are likely to be evident primarily in the few families particularly well represented in the data set, e.g. the pomacentrids and pomacanthids. It is also difficult to evaluate intraspecific variation. Our data suggest that individual variation in egg sizes, sizes of newly hatched larvae and planktonic durations is often slight relative to interspecific differences. However, egg size is known to vary both regionally and seasonally in some tropical invertebrates (Lessios 1987) and temperate fishes (Williams 1967. Bagenal 1971). Further, planktonic larval durations vary more widely among individuals in some families and species than others (Brothers 1984, Victor 1986) and in some species even differs among sites (Thresher et al. 1986, Thresher et al. 1989). Hence, we suggest our regional comparisons will prove robust for those families, such as pomacentrids and pomacanthids, that exhibit relatively slight intraspecific variation. For others, such as the labrids, gobiids and muraenids, strong conclusions will require far more extensive data sets than are currently available.

Concordant patterns of regional variation on several taxonomic levels and among unrelated families helps ameliorate the effects of small sample sizes and also implies a response to factors more pervasive than 'chance' differences in the systematic distributions of different faunas. Both small eggs and unusually long planktonic durations, for example, are repeatedly indicated for Hawaiian endemic fishes in several, though most likely not all families, suggesting a common response to problems faced by a range of these endemic species. On an inner-oceanic scale, it is selfevident that at least part of the differences in both the means and variances of egg sizes, planktonic durations and the like between western Atlantic and western and central Pacific damselfishes can be attributed to dominance of the genus Stegastes on New World reefs (a 'chance' systematic effect?). Throughout its range, members of this genus consistently have small eggs, small larvae at hatching and long planktonic durations. Nonetheless, these same features characterize all 3 western Atlantic genera, not just Stegastes. The probability that only 3 such 'long duration' genera would be drawn at random from the total pomacentrin genus pool is less than 0.001 , which leads us to conclude that some factor(s) has selected for this suite of characteristics in the western Atlantic. That parallel inter-oceanic differences are also evident in chromins, blennies and apogonids reinforces this conclusion.

The consistent co-variance of egg sizes, sizes of newly hatched larvae and larval durations among regions suggests that these parameters are not evolutionarily independent, a point also indicated by correlations among these variables within families. We suspect that other life history features are also tied in to this complex. Adult size co-varies with egg size in some pelagic spawning families (e.g. Thresher \& Brothers 1985, Thresher 1988a), for example, and relative fecundity (fecundity relative to body size) almost certainly varies with egg size, based on literature for other fish groups (Blaxter 1969, Wooton 1979). Whether the latter implies that Atlantic demersal spawning fishes have higher lifetime fecundities, or a higher rate of egg production that their Pacific counterparts, is not known, but would be relatively simple to determine once adequate data are collected. The linkages between life history features suggest that regional variations represent a pooled response to simultaneous selection acting on an entire suite of characteristics. Unfortunately, this is likely to make it difficult to identify any specific, single factor that underlies these regional variations.

Indeed, as yet there are not enough data on enough families and sites to disentangle the myriad historical and current selective factors that can be invoked to account for regional variations in life history features at any spatial scale. The trend for increasingly long planktonic durations among pomacentrid species distributed across the central Great Barrier Reef, for example, may relate to cross-shelf variability in patterns or prospects of larval dispersal, levels of benthic or planktonic productivity, the type and intensity of predation on eggs, larvae or adults, or some historical factor associated with sea level changes that is wholly unrelated to any of the above. Detailed data for other 
families and other reefs may permit falsification of at least some of these hypotheses. The same is true for broader scale variation within the Indo-Pacific. We know that regional variations in life history features similar to those in reef fishes also occur on comparable spatial scales in at least some invertebrate groups, e.g. the genus Conus (cone shells) (Perron \& Kohn 1985), but more detail is required before substantive conclusions can be drawn.

In that regard, the Hawaiian fauna could prove to be a particularly accessible and relatively easily studied system in which to test the ubiquity and consequences of variations in early life history features. Two broadly different hypotheses can be proposed to account for the Hawaiian characteristics. On the one hand, small eggs and long planktonic durations may have evolved among Hawaiian species (including cone shells) as a specific response to some particular feature of the islands, such as the seasonality or magnitude of local water column productivity, patterns of larval dispersal or retention, or some other, as yet unidentified element of the larval or adult environment. On the other hand, long planktonic durations could also be an inevitable consequence of the isolation of the Hawaiian Islands. Of the myriad western and broadly central Pacific species of reef fishes, few with mean planktonic durations less than 35 to $40 \mathrm{~d}$ occur in the Hawaiian Islands (Brothers \& Thresher 1985, Thresher et al. 1989). We have previously interpreted this as supporting the role of long planktonic dispersal times in populating relatively isolated reef areas in the Pacific, including Hawaii. If Hawaiian endemic species have evolved primarily from individuals dispersed to the islands from elsewhere in the central Pacific (for a contrary argument based on vicariance biogeography see Springer 1982), then the inability of species (and individuals?) with short planktonic durations to reach the islands may have pre-disposed Hawailan endemics to a long planktonic duration irrespective of local conditions. These hypotheses could be tested by analysis of the systematic breadth of long planktonic durations among Hawaiian species, by comparisons between the endemics and their sister species at other sites, and by searching for parallel correlations between environmental features (or degrees of isolation) and the life history features of fishes at such sites. Moreover, species recently introduced to Hawaii could provide a powerful direct test of such hypotheses if they show evidence of a shift away from the ancestral condition and towards egg sizes and planktonic durations typical of other species in Hawaii.

On a still broader geographic scale, data drawn from sites and species broadly distributed across both areas continue to support the hypothesis that elements of the early life history of at least some families of reef fishes vary consistently between the tropical western Atlantic and the tropical western and central Pacific. Indeed, the magnitude of differences between oceans in some features, e.g. egg sizes in apogonids, greatly exceeds the documented range of variation within either ocean alone, suggesting that no additional sampling is likely to alter greatly the fundamental difference between oceans. Our data suggest inter-oceanic differences in the means and variances of egg sizes, in the sizes of newly hatched, first-feeding larvae, in the duration of the planktonic larval stages and in the growth rates of these larvae. To date, we can document inter-oceanic differences for all 4 early life history features only in the damselfishes, which constitute by far the largest and most nearly complete of our data sets. The extent to which these life history features seem to co-vary, however, suggests that eventually the full range of differences will be documented for the apogonids and blenniids, as well. In all instances, evidence for these differences has emerged only in demersal spawning taxa we have no data that even suggest comparable differences between the western Atlantic and western and central Pacific differences in any family of pelagic spawning fishes (see also Victor 1986).

Two general classes of hypotheses can be proposed to account for these interoceanic differences. First there may be or have been strong selection among western Atlantic fishes for extreme values of one reproductive feature, such as long planktonic durations or high individual fecundity, as a by-product of which such fishes also produce small eggs and newly hatched larvae and have low mean rates of larval growth. For example, mean planktonic duration in both pomacenthrids and pomacanthids correlates interspecifically with increased variance in age at settlement, which could indicate that the period over which larvae are competent to settle increases as planktonic duration increases. Hence, perhaps larvae of Atlantic fishes recruit to a narrower range of suitable substrata or are subject to current patterns that, on average, are less favorable for the return of larvae to reefs than in the Pacific, either or both of which may select for increased flexibility of age at settlement. Alternatively, western Atlantic fishes may face higher levels of pre-recruitment predation or adult mortality than their western Pacific counterparts, which might dictate maximizing the number or rate at which offspring are produced in order to ensure adequate levels of recruitment. Some of these hypotheses can be falsified by detailed comparisons between regions of mortality schedules of larvae, juveniles and adults. If regional differences derive from historical selection, however, they may remain essentially unfalsifiable.

The second general class of hypotheses follows from current theories regarding optimal allocation of resour- 
ces to offspring (e.g. Smith \& Fretwell 1974, Stearns 1976). We speculate that there is a fundamental difference between the larval environments of the 2 regions that has resulted in some western Atlantic fishes reaching a different balance between fecundity and provisioning of individual young than has been reached by their relatives in the western Pacific. The apparent consequences of producing eggs of different sizes suggests 2 likely possibilities regarding the nature of this difference. Small eggs produce small larvae at hatching. Small larval size, in turn, has been associated with high rates of larval mortality (which limited experimental data suggest to be disproportionately higher for small larvae, e.g. Theilacker \& Lasker 1974, Bailey 1984). Hence, one possible difference between the western Atlantic and western and central Pacific is that, on average, predation fields on very small larvae are less intense in the Atlantic than in the Pacific, such that Atlantic fishes can produce large numbers of small offspring without incurring disproportionately high levels of larval mortality. Small eggs also result in larvae that are small at first feeding. This, in turn, has been associated in the literature with reduced mean size of prey at first feeding (Marak 1960, Arthur 1976, Theilacker \& Dorsey 1980), a narrower range of acceptable prey sizes, an increased cost/benefit ratio of hunting (Jones \& Hall 1974, Arthur 1976) and a shorter period to irreversible starvation should larvae fail to find food when they first become competent to feed (Blaxter \& Hempel 1963, Houde 1974, Theilacker 1981). These feeding-related consequences of small larval size suggest that small larvae cope best when food availability is high, which presumably underlies earlier suggestions (Cushing 1967, Bagenal 1971) that all else being equal egg sizes in fishes are generally smaller when levels of water column productivity are high. Hence, a second possible difference between the larval environments of the 2 oceanic regions is that the micro-zooplanktonic prey of first-feeding larvae are, on average, more abundant (or more predictable in occurrence) in the western Atlantic than in the western Pacific, which has permitted fishes to invest fewer resources in each offspring.

Both of these hypotheses are falsifiable, though the data required to do so (e.g. comparative information on the mortality schedules or predation fields for larvae in comparable portions of the tropical western Atlantic and western and central Pacific, parallel measurements of micro-zooplankton abundance in each region) are not yet available. Indirect evidence, however, may be generally consistent with the productivity hypothesis. Temporal instability of the tropical Pacific, in the form of El Niño-Southern Oscillation Events, greatly exceeds comparable variability of the western Atlantic, coincides with major alterations of circulation patterns and patterns of productivity (Barber \& Chavez 1983) and occurs irregularly, but frequently (Quinn et al. 1978). Such variability could correspond with a lower ability to predict zooplankton abundance in the western Pacific, and could dictate increased provisioning of offspring to ensure successful reproduction during atypical years. In addition, global maps of phytoplankton production (Koblentz-Mishke et al. 1970, in Parsons et al. 1977; but see also Hinga 1985) and zooplankton biomass (Vinogradov 1983) and counts of particles in the water column (Sheldon et al. 1972) suggest that reef-associated regions of the western Atlantic may well be, on average, more productive than comparable sections of the western Pacific. Higher levels of water column productivity in the western Atlantic are also suggested by other biotic differences between reef communities of the 2 regions, such as the relative abundance of heterotrophic and photosynthetic sponges (Wilkinson 1987), and was the main conclusion reached at a UNESCO-COMAR workshop on interoceanic and regional differences in tropical coastal ecosystems, held at the University of the South Pacific, Suva, Fiji, in March 1986 (Birkeland 1987). To what extent these differences are real, and apply to those habitats inhabited by and those zooplankters fed on by the larvae of pomacentrids and other demersal spawning reef fishes, remains unclear, however. The productivity hypothesis also does not seem intuitively consistent with the observation that mean rates of larval growth are lower in the tropical Atlantic than in the Pacific

Each of these hypotheses can be falsified, though the suite of selective factors that could lead to observed regional differences in reproduction is so broad that falsification may be difficult. Two lines of investigation, we suspect, may prove particularly useful in unraveling the numerous complementary hypotheses regarding the causes of inter-oceanic differences in early life histories. First, why do these differences characterize only some, but not all demersal spawning groups, and perhaps no pelagic spawning families? At this point, we have numerous ideas, but no firm data. The eggs of pelagic spawning fishes are overall as variable in size as those of demersal spawners (Thresher 1988a), but seem to typically lack a spatial component to that variability. Among demersal spawning taxa, the apparent lack of inter-oceanic differences in egg sizes among gobies probably reflects only our small sample sizes for the family, which do not yet begin to encompass its diversity. Hoese (1984) recognized 4 subfamilies in the Gobiidae, but also noted that further studies may considerably expand the number'. In at leasts some families of reef fishes (e.g. pomacentrids), early life history characteristics differ significantly between sub-families. If also true for gobies, then pool- 
ing across sub-families for regional comparisons, which is currently the case, could be increasing the variance within regions to the extent that otherwise significant differences are being obscured (Thresher 1988a). On the other hand, the pomacentrin genus Stegastes unambiguously differs from other demersal spawning taxa in showing little or no regional variation in its early life history traits. An important clue to the factors that select for such regional variations might lie in determining in what way species of Stegastes are more similar to a typical pelagic spawning family than they are to other demersal spawning groups. For example, larvae of most demersal spawning fishes tend to be found closer inshore than those of most pelagic spawning families (e.g. Leis \& Miller 1976, Richardson \& Pearcy 1977, Leis \& Goldman 1984). We wonder whether Stegastes larvae occur farther off-shore than those of other pomacentrid genera. In that regard, Richards' (1984) comment that in the Caribbean goby larvae form an important component of the oceanic (e.g. off-shore) ichthyoplankton' is intriguing.

The second approach likely to be of considerable value in understanding inter-oceanic variation in reproduction is to test hypotheses raised against conditions in other oceanic regions. In particular, the wellestablished high levels of water column productivity in the eastern Pacific could test the hypothesis that regional variation in egg sizes and associated life history features are a response to regional differences in such productivity, i.e. fishes in the eastern Pacific should have smaller eggs, smaller larvae at hatching and longer planktonic durations than their confamilials in either the western Atlantic or western and central Pacific. Data for most demersal spawning families are too sparse to test this hypothesis, though preliminary data do not unambiguously support it. As noted earlier, our limited data on eastern Pacific demersal spawning species suggest they are generally similar to related species in the western Atlantic, although, as also noted, the planktonic duration of the eastern Pacific sergeant major Abudefduf troschelii is shorter than that of the western Atlantic A. saxatilis (albeit also significantly longer than that of the widely distributed western Pacific A. vaigensis). Among pelagic spawners, data for labrids may be consistent with the productivity hypothesis. Based on Victor (1986), it appears that wrasses in the eastern Pacific have longer planktonic durations than their congeners elsewhere. Although Victor (1986) discounts water column productivity as a factor selecting for long planktonic durations in eastern Pacific labrids, he does so based on the incorrect expectation that planktonic duration correlates negatively with levels of water column production. If long planktonic durations among eastern Pacific wrasses are a response to high levels of production, it is not at all clear why a pelagic spawning group would show the expected shift in life history features, where demersal spawning taxa apparently do not.

In the end, the only thing that is clear from the discussion above is that the factors underlying regional variation in the early life history features of reef fishes and the generality of these variations across genera, families and spawning modes remain very much unknown. The data are spotty in distribution, and at this stage can only suggest possible types and scales of regional variation. As a result, our comments above range from apologetic to speculative. Nonetheless, we suggest that even the limited data yet available suffice to demonstrate that regional variations in early life history features do occur across several families and on a range of spatial scales. This variation may provide a powerful means of assessing the evolutionary ecology of reproduction in these animals, and certainly justifies caution in naive integration of data from different sites into global theories of reef fish ecology.

Acknowledgements. We thank A. Gronell, W N. McFarland and $N$. Wolf for discussions of this work as it progressed, L. Bell, D. Bellwood, B. Bruce, B. Carlson, P. L. Colin, G. Dingerkus, R. Greenfield, A. Gronell, J. T Moyer, T Present, R. Rosenblatt, P. F. Sale, D. Williams and the staff at the CARMABI Research station (Curacao, Netherland Antilles) for providing specimens, and S. Blaber, G. Harris, D. Tranter and 2 anonymous reviewers for critical comments on the manuscript. We particularly thank G. Meyers and D. Tranter for discussions regarding possible regional differences in physical oceanography and zooplankton ecology, respectively. This work was supported in part by Hatch Grant NYC-183416 to E. B. Brothers. Field work by R. E. Thresher was supported by the Australian Research Grants Committee, the Hawaiian Undersea Research Laboratory (NOAA), the University of Sydney, the Tatsuo Tanaka Memorial Biological Laboratory and grant no. 3486-87 from the National Geographic Society.

\section{NOTE ADDED IN PROOF}

Wellington, G. M., Victor, B. C. (1989), 'Planktonic larval duration of one hundred species of Pacific and Atlantic damselfishes (Pomacentridae)', Mar. Biol. 101, 557-567, recently detail an inter-oceanic comparison based on the family that constitutes our primary data set. Their data suggest that species in the Eastern Pacific have Ionger planktonic durations than those in either the western Atlantic or western Pacific, which is consistent with the productivity hypothesis discussed above, and indicate for the pomacentrins, at least, the same general inter-oceanic difference in planktonic duration that we describe, i.e., a typical western Atlantic pomacentrin has a planktonic duration significantly longer than that of a typical pomacentrin in the western Pacific. Nonetheless, our data sets differ markedly at numerous points. Species' mean planktonic durations 
estimated in the 2 studies correlate poorly $\left(\mathrm{R}^{2}=0.31, \mathrm{n}\right.$ $=46$ species in common), and differ conspicuously for some individual genera (e.g. Amphiprion) and for western Atlantic species in general.

We are unable to account for these differences. For the reasons summarized above and detailed by Thresher et al. (1989), we feel our estimates of planktonic duration and interpretations of them are robust. In particular, we note that for one of the genera where the studies differ most, Amphiprion, our estimates were validated by examination of laboratory-reared larvae of known age. Wellington \& Victor did not test the accuracy or precision of their protocol on any species, though they do refer to their own 'unpublished data', not included in their manuscript, on otolith development in juveniles of one. That their estimates of planktonic duration for Amphiprion spp. are almost exactly twice those we validated suggest strongly to us that Wellington \& Victor may not have discriminated accurately between daily increments and the day-night subdaily bands that are prominent in the otoliths of Amphiprion and some other pomacentrid genera.

\section{LITERATURE CITED}

Albrecht, H. (1969). Behavior of four species of Atlantic damselfishes from Columbia, South America (Abudefduf saxatilis, A. taurus, Chromis multilineata, C. cyanea; Pisces: Pomacentridae). Z. Tierpsychol. 26: 662-676

Allen, G. (1972). Amonefishes. Tropical Fish. Hobb. Publ., Neptune, New Jersey

Allen, G. (1975). Damselfishes of the South seas. Tropical Fish Hobb. Publ., Neptune, New Jersey

Allen, G. (1976). How many sergeant majors? Mar. Aquar 7 . $33-41$

Arthur, D. K. (1976). Food and feeding of larvae of three fishes occurring in the California Current, Sardinops sagax, Engrauiis mordax, and Trachurus symmetricus. Fish. Bull. U.S. 74: 517-530

Bagarino, T., Thia-eng, C. (1986). Egg size and larval size among teleosts: implications to survival potential. in: MacLean, J. L., Dizon, L. B., Hosillos, L. V. (eds.) The first Asian fisheries Forum. Asian Fish. Soc., Manilla, Phil., p. 651-656

Bagenal, T. B. (1971). The interrelation of the size of fish eggs, the date of spawning and the production cycle. J. Fish Biol. 3: $207-219$

Bailey, K. M. (1984). Comparison of laboratory rates of predation on five species of marine fish larvae by three planktonic invertebrates; effects of larval size on vulnerability. Mar Biol. 79: 303-309

Barber, R. T., Chavez, F. P. (1983). Biological consequences of El Niño. Science 222: 1203-1210

Barlow, G. W. (1961). Cause and significance of morphological variation in fishes. Syst. Zool. 10: 105-117

Bell, L. (1976). Notes on the nesting success and fecundity of the anemone fish Amphiprion clarkii at Miyaki-jima, Japan. Jap. J. Ichthyol. 22: 207-211

Birkeland, C. (ed.) (1987). Comparison between Atlantic and Pacific tropical marine coastal ecosystems: community structure, ecological processes, and productivity. UNESCO Rep. Mar. Sci. 46

Blaxter, J. H. S. (1969). Development: eggs and larvae. In Hoar, W. S., Randall, D. J. (eds.) Fish physiology, Vol. 3. Academic Press, New York, p. 177-252

Blaxter, J. H. S., Hempel, G. (1963). The influence of egg size on herring larvae (Clupea harengus L.). J. Cons. Perm. int. Explor Mer 28: 211-240

Bohnsack, J. A., Talbot, F. H. (1980). Species-packing by reef fishes on Australian and Caribbean reefs: an experimental approach. Bull. mar Sci. 30:710-723

Brawley, S. H., Adey, W. H. (1977). Territorial behavior of threespot damselfish (Eupomacentrus planifrons) increases algal biomass and productivity. Environ. Biol. Fish. 2: $45-51$

Briggs, J. D. (1974). Marine zoogeography. McGraw-Hill, New York

Brothers, E. B. (1984). Otolith studies. In: Moser, G. et al. (eds.) Ontogeny and systematics of fishes. Amer. Soc. Ichthyol. Herpetol., Spec. Publ. 1, p. 50-57

Brothers, E. B., Mathews, C. P., Lasker, R. (1976). Daily growth increments in otoliths from larval and adult fishes. Fish. Bull. U.S. 74: 1-8

Brothers, E. B., McFarland, W. N. (1981). Correlations between otolith microstructure, growth and life history transitions in newly recruited French Grunts [Haemulon flavolineatum (Desmarest), Haemulidae]. Rapp. P. v. Réun. Cons. int. Explor Mer 178: 369-374

Brothers, E. B., Thresher, R. E. (1985). Pelagic duration, dispersal and the distribution of Indo-Pacific coral-reef fishes. In: Reaka, M. L. (ed.) The ecology of deep and shallow coral reefs, Vol 3. NOAA Spec. Publ. Rockville, Md., p. $53-69$

Brothers, E. B., Williams, D. M., Sale, P. F. (1983). Length of larval life in twelve families of fishes at 'One Tree Lagoon', Great Barrier Reef, Australia. Mar. Biol. 76: 319-324

Burgess, W. (1978). Butterflyfishes of the world. Trop. Fish Hobb. Publ., Neptune, New Jersey

Colin, P. L. (1975). Neon gobies. Trop. Fish. Hobb. Publ. Inc., Neptune, New Jersey

Cushing, D. H. (1967). The grouping of herring populations. J. mar. biol. Ass. U.K. 47: 193-208

Dale, G. (1978). Comparative ecology of the cardinalfishes of the Bahamas: a study of competition, species diversity, and related factors. Ph. D. diss., City Univ. New York, New York

Edwards, R. R. C. (1984). Comparison of growth in weight of temperature and tropical marine tish counterparts. Can. J. Fish. Aquat Sci. 41: 1381-1384

Ehrlich, P. R. (1975). The population biology of coral reef fishes. Ann. Rev. Ecol. Syst. 6: 211-247

Ekman, S. (1953). Zoogeography of the sea. Sidgwick and Jackson, London

Emery, A. R. (1973). Comparative ecology and functional osteology of fourteen species of damselfish (Pisces: Pomacentridae) at Alligator Reef, Florida Keys. Bull. mar Sci. 23: 649-770

Fricke, H.W. (1974). Öko-ethologie des monogamen Anemonenfisches Amphiprion bicinctus (Freiwasseruntersuchung aus dem Roten Meer). Z. Tierphyschol. 36 : $429-512$

Gladfelter, W. B., Johnson, W. S. (1983). Feeding niche separation in a guild of tropical reef fishes (Holocentridae) Ecology 64: 552--563

Gladfelter, W. B., Ogden, J. C., Gladfelter, E. H. (1980) Similarity and diversity among coral reef fish communities: a comparison between tropical western Atlantic (Virgin 
Islands) and tropical central Pacific (Marshall Islands) patch reefs. Ecology 61: 1156-1168

Grimes, C. B. (1988). Reproductive biology of the Lutjanidae: a review. In: Polovina, J. J., RaIston, S. (eds.) Tropical snappers and groupers: biology and fisheries management. Westview, Boulder, Colorado, p. 239-294

Hale, H. M. (1947). Evidence of the habit of oral gestation in a south Australian marine fish, Apogon conspersus Klunziger. S. Aust. Natur. 24

Hinga, K. R. (1985). Evidence for a higher average primary productivity in the Pacific than in the Atlantic Ocean. Deep Sea Res. 32: 117-126

Honda, S., Imai, S. (1973). Breeding and early development of a pomacentrid, Pomacentrus nagasakiensis Tanaka in an aquarium. Mem. Fac. Fish. Kagoshima Univ. 20: 95-106

Houde, E. D. (1974). Effects of temperature and delayed feeding on growth and survival of larvae of three species of subtropical marine fishes. Mar. Biol. 26: 171-185

Hussein, N., Higuchi, M. (1980). Larval rearing and develop ment of the brown spotted grouper, Epinephelus tauvina (Forskal.) Kuwait Inst. Sci. Rep., p. 1-14

Jablonski, D., Lutz, R. A. (1983). Larval ecology of marine benthic invertebrates: paleobiological implications. Biol. Rev. Cambridge Phil. Soc. 58: 21-89

Johannes, R. E. (1978). Reproductive strategies of coastal marine fishes in the tropics. Environ. Biol. Fish. 3: 65-84

Jones, R., Hall, W. B. (1974). Some observations on the population dynamics of the larval stage in the common gadoids. In: Blaxter, J. S. (ed.) The early life history of fish. Springer-Verlag, Berlin, p. 87-102

Koblentz-Mishke, O. J., Volkovisnky, V V., Kabanova, J G. (1970). Plankton primary production of the world ocean. In: Scientific exploration of the South Pacific. Nat. Acad. Sci., Washington, D.C., p. 183-193

Kuiter, R. H. (1988). Notes on hatching and raising seadragons. Seascope 5: 1-3

Lassuy, D. R. (1980). Effects of 'farming' behaviour by Eupomacentrus lividus and Hemiglyphidodon plagiometopon on algal community structure. Bull. mar. Sci. 30: 304-312

Leis, J. M., Goldman, B. (1984). A preliminary distributional study of fish larvae near a ribbon coral reef in the Great Barrier Reef. Coral Reefs 2: 197-203

Leis, J. M., Miller, J. M. (1976). Offshore distributional patterns of Hawaiian fish larvae. Mar Biol. 36: 359-367

Lessios, H. A. (1987). Temporal and spatial variation in egg size of 13 Panamanian echinoids. J. exp. mar. Biol. Ecol. $114: 217-239$

Limbaugh, C. (1964). Notes on the life history of two Californian pomacentrids: Garibaldis, Hypsypops rubicunda (Girard), and Blacksmiths, Chromis punctipinna (Cooper). Pacif. Sci. 17: 41-50

Low, R. M. (1971). Interspecific territoriality in a pomacentrid reef Eish, Pomacentrus flavicauda Whitley. Ecology 52: 648-654

Marak, R. R. (1960). Food habits of larval cod, haddock and coalfish in the Gulf of Maine and George's Bank area. J. Cons. Perm. int. Explor Mer 25: 147-157

Marshall, N. B. (1953). Egg size in Arctic, Antarctic and deepsea fishes. Evolution 7 328-341

Moe, M. A., Jr. (1976). Rearing Atlantic angelfish. Marr. Aquarist $7: 17-26$

Montgomery, W. L. (1980). The impact of non-selective grazing by the giant blue damselfish. Microspathodon dorsalis, on algal communities in the Gulf of California, Mexuco. Bull. mar Sci. 30: 290-303

Moyer, J. T., Thresher, R. E., Colin, P L. (1983). Courtship, spawning and inferred social. organization of American angelfishes (genera Pomacanthus, Holacanthus and Cen-

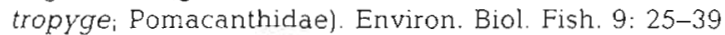

Panella, G. (1980). Growth patterns in fish sagittae. In: Rhoads, D. C., Lutz, R. A. (eds.) Skeletal growth of aquatic organisms. Plenum, New York, p. 519-560

Parrish, J. (1989). Characteristics of fish communities on coral reefs and in potentially interacting shallow habitats in tropical oceans of the world. Mar. Ecol. Prog. Ser. (in press)

Parsons, T R., Takahashi, M.. Hargrave, B. (1977). Biological oceanographic processes. Pergamon, Oxford

Perron, F. E., Kohn, A. J. (1985). Larval dispersal and geographic distribution in coral reef gastropods of the genus Conus. Proc. Fifth Internat. Coral Reef Symp. 4: 95-100

Potthoff, T., Kelley, S., Saksena, V., Moe, M., Young, F. (1987). Description of larval and juvenile yellowtail damselfish, Microspathodon chrysurus, Pomacentridae, and their osteological development. Bull. mar. Sci. 40: 330-375

Quinn, W. H., Zopt, D. O., Short, K. S., Kuo Yang, R. T W. (1.978). Historical trends and statistics of the southern oscillation, El Niño, and Indonesian droughts. Fish. Bull. U.S. 76: 663-678

Radtke, R. L. (1984). Formation and structural composition of larval striped mullet otoliths. Trans. Am. Fish. Soc. 113: 186-191

Radtke, R. L., Deàn, J. M. (1982). Increment formation of the otoliths of embryos, larvae and juveniles of the mummichog, Fundulus heteroclitus. Fish. Bull. U.S. 80: 201-215

Randall, J. E. (1961). A contribution to the biology of the convict surgeonfish of the Hawaiian Islands, Acanthurus triostegus sandivensis. Pacif. Sci. 15: 215-272

Rass, T. S. (1941). Analogous or parallel variations in structure and development of fishes in northern and arctic seas. Jubilee Publ. Mosc. Soc. Natural. 1805-1940: 1-60

Richards, W. J. (1984). Kinds and abundances of fish larvae in the Caribbean Sea and adjacent areas. NOAA tech. Rep. NMFS SSRF 776: 1-54

Richardson, S. L., Pearcy, W G. (1977). Coastal and oceanic fish larvae in an area of upwelling off Yaquina Bay, Oregon. Fish. Bull. U.S. 75: 125-145

Robertson, D. R., Hoffman, S. (1977). The roles of female mate choice and predation in the mating systems of some tropical labroid fishes. Z. Tierpsychol. 45: 298-320

Russell, B. C. (1971). Underwater observations on the reproductive activity of the demoiselle Chromis dispilis (Pisces: Pomacentridae). Mar. Biol. 10: 22-29

Sale, P. F. (1980). The ecology of fishes on coral reefs. Ann Rev. Oceanogr. Mar. Biol. 18: 367-421

Sheldon, R. W., Prakash. A., Sutcliffe, W H.., Jr. (1972). The size distribution of particles in the ocean. Limnol. Oceanogr 17: $327-340$

Smith, C. C. Fretwell, S. D. (1974). The optimal balance between size and number of offspring. Am. Nat. 108: $499-506$

Smith, C. L. (1978). Coral reef fish communities: a compromise view. Environ. Biol. Fish. 3: 109-128

Springer, V. G. (1982). Pacific Plate biogeography, with special reference to shore fishes. Smithson. Contribu. Zool. 167: $1-183$

Stearns, S. C. (1976). Life-history tactics; a review of the ideas. Q. Rev. Biol. 51 3-47

Strathmann, R. R. (1977). Egg size, larval development and juvenile size in marine benthic invertebrates. Am. Nat. 111: $373-376$

Suzuki, K., Hioki, S., Kashihara, M. (1985a). Life history of the damselfish Pomacentrus coelestis in Suruga Bay, Japan. J. Fac. Mar. Sci. Technol., Tokai Univ. 21 99-114 
Suzuki, K., Hioki, S., Kurita, M. (1985b). Life history of the damselfish Chromis notatus in Suruga Bay, Japan. J. Fac. Mar Sci. Technol, Tokai Univ, 21: 115-127

Talbot, F. H., Gilbert, A. J. (1981). A comparison of quantitative samples of coral reef fishes latitudinally and longitudinally in the Indo-West Pacific. Proc. Fourth Coral Reef Symp. 2: 485-490

Theilacker, G. H. (1981). Effect of feeding history and egg size on the morphology of jack mackerel, Trachurus symmetricus, larvae. Rapp. P. v. Réun. Cons. int. Explor Mer 178 : $432-440$

Theilacker, G. H., Dorsey, K. (1980). Larval fish diversity, a summary of laboratory and field research. In: Sharp, G. D. (ed.) Workshop on the effects of environmental variation on the survival of pelagic larval fishes. UNESCO, Rome, p. 105-167

Theilacker, G. H., Lasker, R. (1974). Laboratory studies of predation by euphausid shrimps on fish larvae. In: Blaxter, J. H. S. (ed.) The early life history of fish. Springer-Verlag, Berlin, p. 287-299

Thresher, R. E. (1976). Field analysis of the territoriality of the threespot damselfish, Eupomacentrus planifrons (Pomacentridae). Copeia 1976: 266-276

Thresher, R. E. (1982). Interoceanic differences in the reproduction of coral-reef fishes. Science 218: 70-72

Thresher, R. E. (1984). Reproduction in reef fishes. Tropical Fish. Hobb. Inc., Neptune, New Jersey

Thresher, R. E. (1985). Interoceanic differences in the early life history of coral reef fishes: Australia versus the western Atlantic. Proc. Ecol. Soc. Aust. 14: 1-5

Thresher, R. E. (1988a). Latitudinal variation in egg sizes of tropical and sub-tropical North Atlantic shore fishes. Environ. Biol. Fish. 21: 17-25

Thresher, R. E. (1988b). Otolith microstructure and the demography of coral reef fishes. Trends Ecol. Evol. 3: 78-80

Thresher, R. E. (in press). Geographic variability in the evolutionary and community ecology of coral reef-associated fishes. In: Sale, P. F. (ed.) The ecology of coral reef fishes. Academic Press, New York

Thresher, R. E., Brothers, E. B. (1985). Reproductive ecology

This review was presented by Dr P. W. Sammarco, Townsville, Australia and biogeography of Indo-West Pacific angelfishes (Pisces; Pomacanthidae). Evolution 39: 878-887

Thresher, R. E., Colin, P. L., Bell, L. (1989). Planktonic duration, distribution and the population structure of western and central Pacific damselfishes (Pomacentridae). Copeia 1989: 420-434

Thresher, R. E., Sainsbury, K. J., Gunn, J. S., Whitelaw, A. W. (1986). Life history strategies and recent changes in population structure in the lizardfish genus, Saurida, on the Australian Northwest Shelf. Copeia 1986: 876-885

Turner, C. H. Ebert, E. E. (1962). The nesting of Chromis punctipinnis (Cooper) and a description of their eggs and larvae. Calif. Fish Game 48: 243-248

Vance, R. R. (1973). On reproductive strategies for marine benthic invertebrates. Am. Nat. 107: 339-352

Victor, B. C. (1983). Settlement and larval metamorphosis produce distinct marks on the otoliths of the slippery dick, Halichoeres bivittatus. In: Reaka, M. L. (ed.) The ecology of deep and shallow coral reefs, Vol. 1. NOAA Spec. Publ., Rockville, Md., p. 47-51

Victor, B. C. (1986). Duration of the planktonic larval stage of one hundred species of Pacific and Atlantic wrasses (family Labridae). Mar. Biol. 90; 317-326

Vinogradov, M. E. (1983). Open-ocean ecosystems. In: Kinne, O. (ed.) Marine ecology, Vol.5, Part 2, Wiley, Chichester, p. $657-737$

Wilkinson, C. R. (1987). Interocean differences in size and nutrition of coral reef sponge populations. Science 236 : $1654-1657$

Williams, G. C. (1967). Identification and seasonal size changes of eggs of the labrid fishes, Tautogolabrus adspersus and Tautoga onitis oft Long Island Sound. Copeia 1967: 452-453

Williams, D. M. (1982). Patterns in the distribution of fish communities across the central Great Barrier Reef. Coral Reefs $1 \cdot 35-43$

Wooton, R. J. (1979). Energy costs of egg production and environmental determinants of fecundity in teleost fishes. In: Miller, J. (ed.) The phrenology of fishes. Academic Press, London, p. 133-159

Manuscript first received: September 21, 1988

Revised version accepted: June 21, 1989 